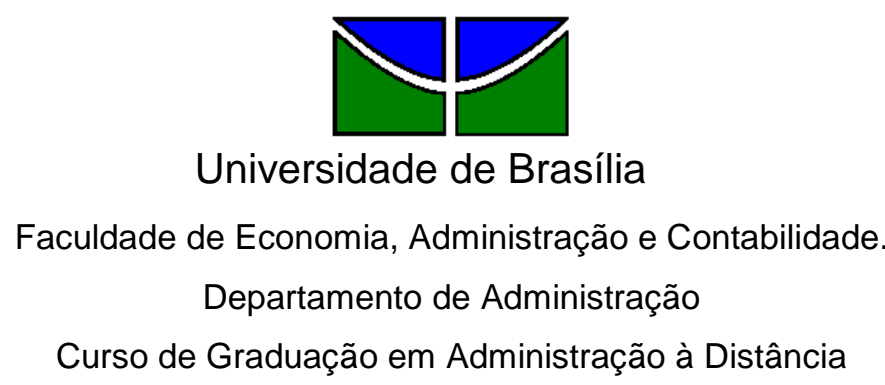

VANESSA DA SILVA ANDRADE SHITSUKA

\title{
AVALIAÇÃO DE REAÇÃO AO TREINAMENTO: UM ESTUDO DE CASO NA ESCOLA DE GOVERNO DO DF (EGOV)
}

Brasília - DF 2010 


\section{VANESSA DA SILVA ANDRADE SHITSUKA}

\section{AVALIAÇÃO DE REAÇÃO AO TREINAMENTO: UM ESTUDO DE CASO NA ESCOLA DE GOVERNO DO DF (EGOV)}

Monografia apresentada a Universidade de Brasília (UnB) como requisito parcial para obtenção do grau de Bacharel em Administração.

Professor Orientador: Msc. Maira Pinto Cauchioli Rodrigues

Brasília - DF 2010 
Shitsuka, Vanessa da Silva Andrade.

Avaliação de Reação ao treinamento: um estudo de caso na Escola de Governo do Distrito Federal (EGOV)/ Vanessa da Silva Andrade Shitsuka. - Brasília, 2010.

54 f.: il.

Monografia (bacharelado) - Universidade de Brasília, Departamento de Administração - EaD, 2010.

Orientador: Prof ${ }^{a}$. Msc. Maira Pinto Cauchioli Rodrigues, Departamento de Administração.

1. Treinamento e Desenvolvimento e Educação 2. Sistemas de Treinamento 3. Avaliação de Treinamento. I. Título. 
VANESSA DA SILVA ANDRADE SHITSUKA

\section{AVALIAÇÃO DE REAÇÃO AO TREINAMENTO: UM ESTUDO DE CASO NA ESCOLA DE GOVERNO DO DF (EGOV)}

A Comissão Examinadora, abaixo identificada, aprova o Trabalho de Conclusão do Curso de Administração da Universidade de Brasília de Vanessa da Silva Andrade Shitsuka.

\section{VANESSA DA SILVA ANDRADE SHITSUKA}

Msc. Maira Pinto Cauchioli Rodrigues

Professor-Orientador

Msc. Antõnio Isidro da Silva Filho

Professor-Examinador
Kesia Rozzett Oliveira

Professor-Examinador

Brasília, 04 de Dezembro de 2010. 


\section{RESUMO}

Este trabalho trata de análise à reação ao treinamento por parte dos servidores participantes de um curso de capacitação na Escola de Governo do Distrito Federal (EGOV), com vistas a verificar as variáveis percebidas positiva e negativamente referentes ao curso oferecido. Na Introdução faz-se uma contraposição entre o significado do trabalho como um todo e a realidade da área de Treinamento e Capacitação num âmbito geral. No Referencial Teórico, abordam-se vertentes acadêmicas e científicas que corroboram para a compreensão da temática sobre TD\&E, assim como se caracterizam os Sistemas de Treinamento e Avaliações de Treinamento. Na parte de Resultados e Discussões, descrevem-se os resultados da pesquisa feita presencialmente junto à turma de alunos treinandos e discutem-se os dados obtidos, contrastando com a teoria abordada outrora. E nas Considerações Finais, perfaz-se o os resultados da pesquisa e sugerem-se melhorias para a instituição analisada.

Palavras-chave: Treinamento e Desenvolvimento, Administração Pública, Avaliação de Reação ao Treinamento. 


\section{SUMÁRIO}

1 INTRODUÇÃO

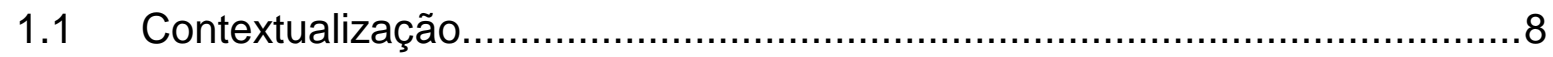

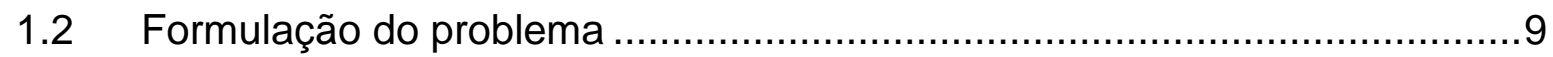

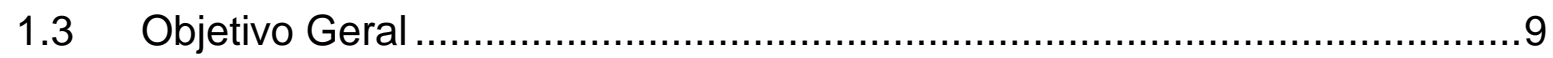

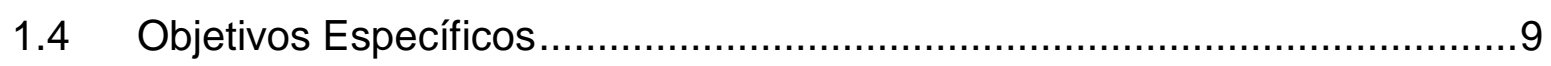

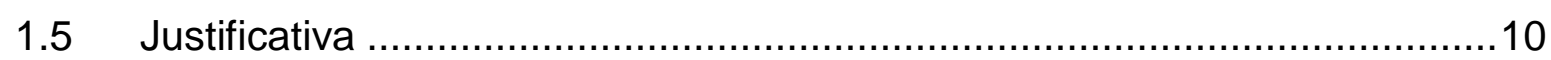

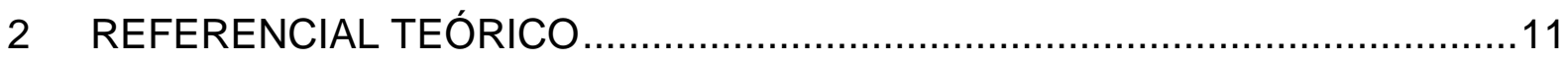

2.1 Treinamento e Desenvolvimento e Educação - conceitos e história ...........11

2.2 Estruturação dos Sistemas de Treinamento ..........................................16

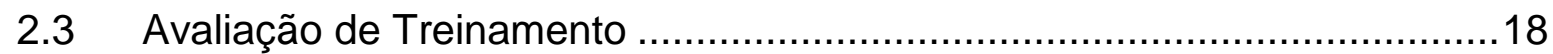

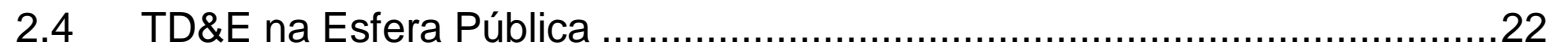

3 MÉTODOS E TÉCNICAS DE PESQUISA …...............................................27

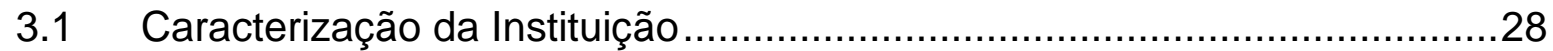

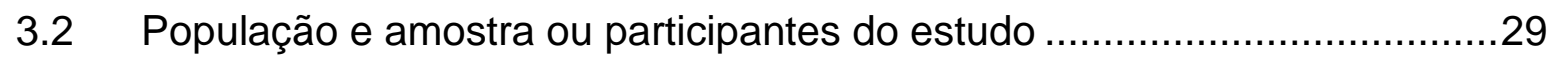

3.3 Caracterização dos instrumentos de pesquisa ........................................29

3.4 Procedimentos de coleta e de análise de dados........................................30

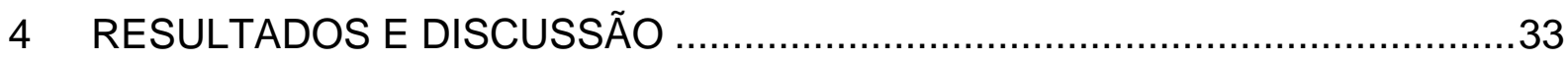

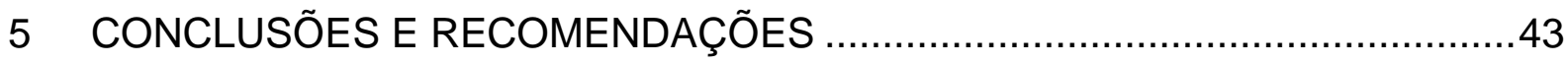

6 CRONOGRAMA DE EXECUÇÃO DAS ETAPAS ……..............................45

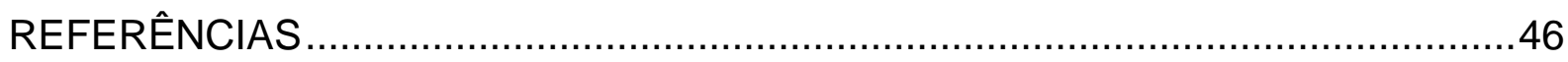

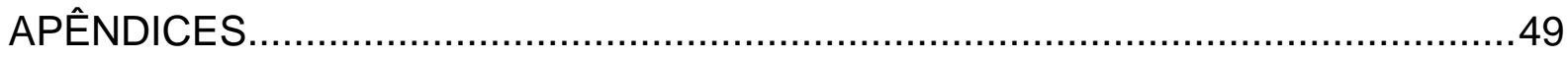

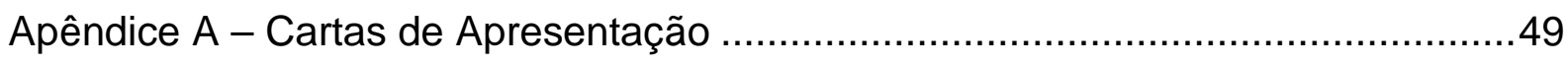

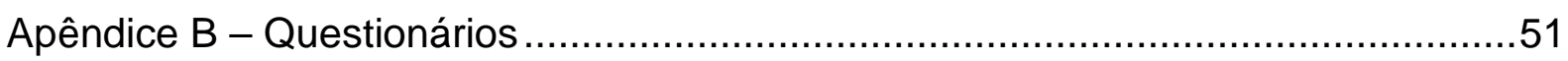




\section{INTRODUÇÃO}

Com a acirrada competitividade e exigência no mundo do trabalho, as pessoas que participam de todo esse processo laborativo - o capital intelectual das organizações - estão sentindo mais a primordialidade de se capacitar, tanto para desempenhar adequadamente suas funções dentro das empresas ou instituições, como também por definição do empregador em qualificar seu corpo funcional para as nuances do mercado de trabalho. Mudanças sócio-econômicas e tecnológicas proporcionaram significativas alterações na estrutura organizacional das empresas e instituições, fazendo com que, automaticamente, houvesse uma demanda instrucional e educacional, ocasionando um conseqüente aumento na autonomia do corpo funcional, reestruturação dos cargos - e por conseguinte nos salários -, assim como na exigência dos níveis de escolaridade e capacitação.

Contudo, ainda há organizações que pouco investem em seus colaboradores, o que não será objeto de estudo deste Trabalho, e em decorrência desta falta de investimento na área de treinamento, deixa-se de assegurar uma maior vantagem competitiva num longo prazo.

Percebe-se que educação é um tema que interessa aos mais diversos setores da sociedade, inclusive o corporativo, e esta está presente no rol de prioridades de todas as organizações que visam aumentar seu poder no mercado. Segundo Bastos (2008), as ações de treinamento, desenvolvimento ou qualificação do trabalhador ocupam um dos papéis centrais no conjunto de práticas em contextos organizacionais, (...) e seus impactos, por sua vez, são fundamentais tanto para os ajustes indivíduo-trabalho que se traduzem em diferenças de desempenhos individuais e coletivos, quanto para as relações entre organização e seus contextos, garantindo-Ihes, ou não, produtividade e competitividade.

Analisando tais práticas dentro do cenário do Ente Público, vertente pela qual este trabalho pretende seguir e trabalhar, é possível verificar que as políticas e práticas de gestão de pessoas são altamente direcionadas pela conjuntura política, social, cultural e administrativa. A capacitação deve ser entendida como um investimento que o Estado precisa fazer em vistas dos resultados que busca alcançar, assim como para a promoção de melhoria da eficiência e efetividade nos trabalhos realizados pelos servidores. Portanto, analisar os recursos financeiros 
aplicados nas ações de treinamento como "gastos" é um equívoco, pois são aplicações de médio e longo prazo que tendem a oferecer excelente retorno à Administração Pública como um todo.

Seja na iniciativa privada ou na esfera pública - especificamente em instituições de médio e grande porte - vários passos são imprescindíveis para a promoção de um treinamento de sucesso, tais como articulação para a consecução e angariação de investimentos; organização e planejamento das ações de capacitação a serem promovidas pela instituição, podendo estas serem terceirizadas; levantamento das necessidades de treinamento (LNT); realização/efetivação do treinamento junto aos colaboradores. Entretanto, após a conclusão de todo o processo - que se dá com a participação do corpo funcional nas ações de treinamento e capacitação - fica o questionamento: quais foram os efeitos do treinamento junto aos participantes? As respostas para tal pergunta advém por meio da avaliação do treinamento.

Segundo Freitas e Borges-Andrade (2004), há uma crescente preocupação entre os pesquisadores e profissionais acerca da avaliação de treinamento, devido, principalmente, ao aumento do volume de investimentos nessa área pelas organizações e à necessidade de mensuração de sua eficácia, tanto em nível individual quanto no organizacional. Também de acordo com os supracitados autores, tal avaliação consiste num mecanismo de realimentação do sistema de treinamento, ao identificar necessidades de aperfeiçoamento nos programas e ao apontar os aspectos positivos, assim como mostrar as contribuições desses programas para os treinandos.

Trazendo tais preceitos teóricos para a égide do presente trabalho, tem-se que este visa descrever uma avaliação de reação de indivíduos treinados por meio de curso de capacitação em organização pública, identificando a eficácia (ou não) do treinamento junto à população analisada. A instituição a colaborar com este Projeto acadêmico é a Escola de Governo do Distrito Federal (EGOV), pelo fato de possibilitar a participação da autora para a averiguação do objetivo desta pesquisa avaliar a reação do servidor após submissão ao treinamento. A EGOV constitui órgão vinculado à Secretaria de Estado de Planejamento, Orçamento e Gestão do Distrito Federal (SEPLAG), que tem como função principal a promoção de cursos de capacitação para servidores de todo o complexo administrativo do Governo do Distrito Federal. 
O trabalho em questão estrutura-se em quatro partes fundamentais: Introdução, Referencial Teórico, Resultados e Discussões e Considerações finais. A Introdução é a presente parte do referido projeto, na qual se faz uma contraposição entre o significado do trabalho como um todo e a realidade da área de Treinamento e Capacitação num âmbito geral. No Referencial Teórico, são descritas algumas vertentes acadêmicas e científicas que corroboram para a compreensão da temática sobre TD\&E, assim como se faz uma breve síntese dos sistemas de treinamento e detalha em que consistem as avaliações de treinamento. Na parte de Resultados e Discussões, aborda-se os resultados da pesquisa feita presencialmente junto à turma de alunos treinandos e discutem-se os dados obtidos, contrastando com a teoria abordada outrora. E nas Considerações Finais, sugerem-se melhorias e a manutenção de pontos favoráveis, assim como se faz um breve retrospecto de todo o referido trabalho.

\subsection{Contextualização}

Dentro do contexto da Administração Pública, mas especificamente no âmbito do Distrito Federal, este trabalho visa investigar e analisar a reação após curso de Capacitação promovido para servidores públicos da esfera Distrital pela EGOV, verificando os efeitos de todo o processo instrucional e qualificativo proposto à turma estudada neste Trabalho.

Nesta época contemporânea, caracterizada por ser a Era da Informação, em meio a qual a tecnologia, atrelada á globalização econômica e social, proporciona novas formas de comunicação e avanço nas organizações, há uma crescente apropriação das práticas de treinamento por parte das empresas, com a finalidade de agregar conhecimentos e novos conceitos aos colaboradores, permitindo sua compreensão à volatilidade informacional pelo qual o mundo está imerso.

Então, pode-se dizer que por meio do treinamento, os servidores públicos adquirem informações e aprimoram práticas relevantes para sua atuação junto ao órgão de vinculação, na execução de suas tarefas e no atendimento ao cidadão, e também, para seu crescimento pessoal e profissional - por isso da importância de se avaliar a importância e a representatividade dos cursos de capacitação por 
avaliação formal (questionário de opinião), a fim de constantemente aperfeiçoar o que está sendo desenvolvido.

\subsection{Formulação do problema}

Para o presente Trabalho, estabeleceu-se como Problema de Pesquisa o seguinte: Qual a reação dos servidores ao treinamento promovido pela EGOV?

\subsection{Objetivo Geral}

Compreende-se como objetivo geral deste trabalho acadêmico: Identificar a reação ao treinamento promovido pela EGOV.

\subsection{Objetivos Específicos}

Quanto aos objetivos específicos referentes ao presente trabalho, verificamse os seguintes:

1) Descrever o perfil dos participantes do treinamento promovido pela EGOV;

2) Identificar as variáveis de reação percebidas positivamente no treinamento promovido pela EGOV;

3) Identificar as variáveis de reação percebidas negativamente no treinamento promovido pela EGOV; 


\subsection{Justificativa}

A pesquisa em questão justifica-se pelas suas peculiaridades, pela relevância quanto ao caráter contributivo que esta tende a apresentar por tratar do de Avaliação de Reação de Treinamento, Desenvolvimento e Educação (TD\&E) na Esfera Pública, pela oportunidade e viabilidade de ser trabalhada, tendo em vista a instituição a oportunizar este Trabalho - a Escola de Governo do Distrito Federal (EGOV) - apresentar projetos nesta área (TD\&E), além de questões pessoais (da autora) que propiciaram e motivaram na realização deste Trabalho.

Impende mencionar, também, a importância da Avaliação de Reação ao Treinamento como justificante para a realização de tal pesquisa, haja vista sua aplicabilidade como instrumento de verificação da efetividade das ações de TD\&E, assim como por ser mecanismo de coleta de dados que possibilitam 0 melhoramento de toda a sistemática que vem a ser o treinamento nas organizações. 


\section{REFERENCIAL TEÓRICO}

Esta seção é destinada à análise da literatura sobre os temas principais trabalhados no presente trabalho: Treinamento, Desenvolvimento e Educação (TD\&E); Sistemas de TD\&E; Avaliação do Treinamento; TD\&E no Ente Público.

Cabe mencionar que na atual conjuntura, o treinamento tem sido objeto de atenção especial das organizações, em função de sua importância para o desenvolvimento e adequação dos colaboradores para a atividade laboral e para a dinâmica econômico-social das instituições, as quais se baseiam no trabalho para os resultados. Dentro dessa vertente organizacional, dedica-se esse espaço para a apreciação de referências teóricas e bibliográficas.

\subsection{Treinamento e Desenvolvimento e Educação - conceitos e história}

O estudo do processo de aprendizagem dentro do ambiente organizacional sempre foi necessário para as organizações Há muito tempo, desde que se estruturou formalmente, que (...) a aprendizagem é fundamental para que as organizações possam atingir seus objetivos (PILATI, 2006).

Ainda segundo Pilati (2006), TD\&E atrai a atenção de profissionais e cientistas há muito tempo, haja vista que o processo de aprendizagem, questão central da área, é foco de interesse dos primeiros pensadores do mundo ocidental. Em virtude de a aprendizagem ser algo bastante presente na vida em sociedade, sua aplicabilidade dentro do contexto laborativo constitui um fenômeno complexo, face à sua amplitude e representatividade.

Conceituando os três pilares do TD\&E (Treinamento, Desenvolvimento e Educação), tem-se que treinamento, conforme conceito proposto por Boog (1994), perfaz a idéia de um processo de preparar pessoas para executar as tarefas exigidas por um posto de trabalho. $\mathrm{O}$ autor complementa, defendendo a tese de que utilizando-se métodos mais ou menos sistemáticos, o processo leva alguém a ser capaz de fazer algo nunca antes realizado por si, e é possível, fazê-lo sem a assistência de quem ensina. 
Para Borges-Andrade et al (2002), o treinamento pode ser visto como um instrumento administrativo de vital importância para o aumento da produtividade do trabalho, e também como um fator de auto-satisfação do treinando, constituindo-se um agente motivador comprovado. Nas organizações contemporâneas, o termo treinamento passou a significar um processo educacional sistematicamente planejado e de curto-prazo com a finalidade de propiciar ao treinando mudanças comportamentais e atitudinais que reflitam no seu desempenho laboral, em vista dos desafios impostos pela expansão acelerada do conhecimento.

Quanto ao Desenvolvimento de Pessoal, entende-se como um processo em que se engloba o treinamento, só que indo além, pois se enfoca o desenvolvimento do indivíduo num contexto geral, reportando as várias formas de aprendizagem, e consequentemente, não se restringindo à sala de aula. Pacheco e Scofano (2008) definem que desenvolvimento de pessoas engloba experiência, vivência, percepção e, principalmente, a capacidade pessoal de cada um. Trata-se de um processo globalizante, no qual se considera os estímulos e conhecimentos absorvidos por toda a vida do indivíduo em questão.

Também se pode compreender desenvolvimento como sendo experiências organizadas de aprendizagem, em um período definido de tempo, para aumentar a possibilidade de melhoria da performance no trabalho e o crescimento (NADLER, 1984 apud VARGAS, 1996).

Com relação à Educação, terceiro pilar do TD\&E, ressalta-se o fato de as demandas por capacitação e as exigências do mundo do trabalho terem feito com que os dois conceitos - Treinamento e Desenvolvimento - não fossem mais suficientes para compreender o conjunto das ações de capacitação presentes nas organizações, sendo necessário acrescentar o conceito de Educação (Mourão, 2009). Canabrava e Vieira (2006) perfazem a definição de Educação como um processo de construção ativa do conhecimento, cultura, valores, crenças, aptidões, por meio da qual se desenvolve um indivíduo participativo, compromissado e transformador.

Subsidiariamente aos três pilares anteriormente explicitados, existem outros dois conceitos importantes que merecem ser abordados: o de informação - que é uma forma de indução de aprendizagem, definida como módulos ou unidades organizados de conhecimentos - e instrução - uma forma mais simples de 
estruturação de eventos de aprendizagem que envolve definição de objetivos e aplicação de procedimentos instrucionais (VARGAS; ABBAD, 2006).

Ainda na visão de Vargas e Abbad (2006), fazendo uma integração entre todos os pilares supracitados - num modelo integrado dos cinco conceitos -, sugerese um diagrama, como o da Figura 01 - que se trata de uma síntese dos conceitos relacionados à capacitação profissional as organizações, dentro de uma relação de representatividade e abrangência dos pilares envolvidos.

Figura 01: Diagrama de Integração dos Cinco Conceitos (Vargas; Abbad, 2006)

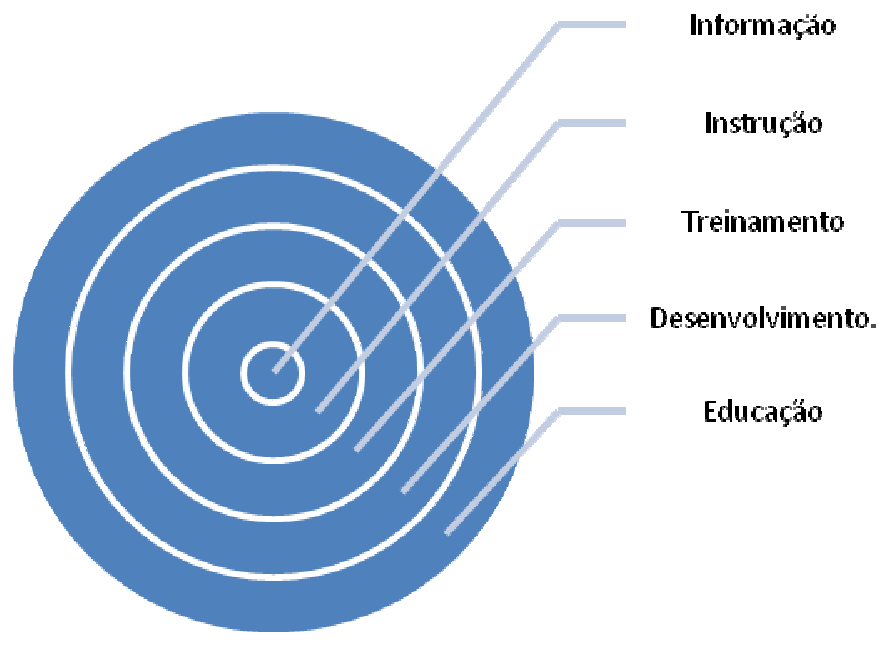

É importante salientar que todas as ações de Treinamento, Desenvolvimento e Educação no contexto das organizações não surgiram do acaso. Há uma trajetória histórica que culminou no que se entende hoje por TD\&E. Observa-se que as primeiras ações envolvendo treinamento e desenvolvimento de pessoas podem ser reportadas aos primórdios da civilização, quando o homem da caverna repassava aos seus descendentes os conhecimentos básicos que asseguravam a sobrevivência e a continuidade da espécie humana (VARGAS; ABBAD, 2006). Ainda segundo as autoras, muitos milênios passaram até que, em face do progresso alcançado pela humanidade, as atividades de treinamento e desenvolvimento de pessoal começassem a ser percebidas, compreendidas, sistematizadas e utilizadas em benefício mais amplo.

Verifica-se que ações de TD\&E se constituíram, de fato, desde o início das organizações industriais - meados do século XIX - como elemento fundamental da gestão de pessoas. Nessa época, a lógica da ação instrucional era a de capacitar os 
trabalhadores para desenvolverem as tarefas prescritas pela organização do trabalho nas plantas fabris. Nesse momento, o papel estava rigorosamente ligado à efetividade do processo industrial. (MALVEZZI, 1994 apud PILATI, 2006).

O crescimento do trabalho especializado, a partir de 1880, redobrou a atenção para o setor de treinamento, destacando-o dos demais produtos da área de recursos humanos nas organizações. Tal crescimento favoreceu a sistematização do treinamento, a fim de garantir qualificação profissional aos trabalhadores - houve uma aproximação entre indústria e escola. Porém, na abordagem de Oliveira e Vanalle (1999), a sistematização do Treinamento, no entanto, ainda se restringia à formulação de programas de treinamento voltados para as habilidades específicas na empresa que, por sua vez, asseguraria a diminuição dos erros operacionais decorrentes da sua mão-de-obra, gerando condições para conseguir o perfil ocupacional desejado, fazendo com que fosse possível inferir que as ações de treinamento ainda levariam certo tempo para serem desvinculadas da idéia de ser uma espécie de "adestramento" para uma finalidade específica.

Apenas a partir de 1930 houve uma maior demanda para estruturar cientificamente as ações de treinamento nas organizações. Isso ocorreu porque os gestores observaram que somente com o uso de tecnologias seria possível incrementar o processo de adaptação do homem ao trabalho prescrito, para que ele adquirisse o repertório mínimo para poder executar suas tarefas (MALVEZZI, 1994 apud PILATI, 2006).

Bastos (1991) apud Pilati (2006) descreve através de quatro ondas a perspectiva histórica das ações de treinamento nas organizações, partindo dos anos de 1950 até os dias atuais. Segundo o autor, a primeira onda, denominada "Treinamento para o trabalho", compreende o período de 1950 a 1970 e inclui ações de treinamento para o desenvolvimento de habilidades técnicas e profissionais voltadas para o desempenho no trabalho. Os recursos humanos eram compreendidos como peças substituíveis no processo produtivo. A segunda onda, denominada "Treinamento para a Gerência e Supervisão", abrange o período de 1960 a 1980 e tem como principais características ações de capacitação com uma maior preocupação em qualificar a mão-de-obra para a operação dos processos tecnológicos dentro das organizações, o que diferencia a perspectiva dos recursos humanos. A terceira onda, caracterizada como sendo "Desenvolvimento Organizacional e Tecnologia do Desempenho", abrangendo os anos de 1970 a 
1990, veio com o aumento da importância da educação aberta e continuada, em que o próprio trabalhador desenvolvia a capacidade de identificar e priorizar suas necessidades de treinamento, individualizando, assim, o processo de TD\&E nas organizações. E por fim, a quarta onda, chamada "Informação, Conhecimento e Sabedoria", perfaz o período que vem desde 1980 até os dias atuais, em que há a ênfase no desenvolvimento da criatividade dos trabalhadores, no preparo para a tomada de decisões e em uma maior exigência das técnicas de mensuração da efetividade das ações de capacitação, viés de estudo deste trabalho.

Fazendo um breve retrospecto das ações de TD\&E no Brasil, o que é importante para este estudo, em virtude de se tratar da realidade nacional e a de contexto da pesquisa em questão, tem-se que a década de 30 pode, realmente, ser tomada como um marco referencial na história da política da educação profissional nacional. Nesta época, iniciava-se o processo de industrialização do País. Com a queda da Bolsa de Nova lorque e a conseqüente crise do setor cafeeiro, era necessário o esforço de produzir mais bens de consumo, que eram até então importados. Essa fase, denominada substituição das importações, “(...) levou à criação de um maior número de escolas superiores para formação de recursos humanos necessários às novas exigências do processo produtivo" (GONÇALVES et al, 2002 apud CANABRAVA; VIEIRA, 2006).

Então, a década de 30-40 e no pós-guerra foram momentos em que surgiram grandes necessidades de pessoal qualificado e treinado para atender à produção das indústrias e empresas.

Desde os primeiros avanços do T\&D no Brasil, até a década de 70, sentiu-se um movimento crescente no desenvolvimento dessas práticas nas organizações. Uma iniciativa importante para ações de Treinamento e Desenvolvimento de Pessoas foi a criação da lei de incentivos fiscais, que beneficiaria empresas que investissem em atividades deste tipo. Segundo Canabrava e Vieira (2006), a Lei no․ 6.297/75 incentivava investimentos em TD\&E e era permitida a dedução em dobro, no Imposto de Renda devido, relativos aos investimentos das empresas em projetos de formação profissional. Nesse período, houve grandes projetos de Treinamento, ampliando a cultura de T\&D no Brasil até 1990.

E com a expansão da tecnologia da informação e das telecomunicações, originou-se a globalização, provocando em pouco tempo efeitos alarmantes na sociedade comercial e industrial, como a excessiva competitividade pelo acirramento 
da concorrência. Tal condição mundial de crescimento e expansão - globalização é a realidade vivenciada pela população mundial no presente momento. Observa-se, atualmente, uma crescente valorização das empresas/ organizações brasileiras em atividades de Treinamento e Desenvolvimento de pessoas, como forma sustentabilidade no mercado, em vistas da explicitada globalização, volatilidade do conhecimento e, também, percebe-se a preconização da construção de educação sólida e contínua, fazendo com que o TD\&E seja constante para a otimização do desempenho global dos colaboradores.

A literatura geral demonstra que houve um aumento crescente no investimento e em ações voltadas para os treinamentos nas organizações, em face de no presente momento, a Era da Informação, em que a tecnologia aliada à globalização econômica decreta novas formas de progresso e comunicação, as empresas não têm alternativas a não ser se empenharem nesta empreitada da modernidade, (...) utilizando-se do treinamento, com a finalidade de manter seus funcionários a par de novas técnicas (CAMPOS et al, 2004).

\subsection{Estruturação dos Sistemas de Treinamento}

As organizações, preocupadas com a manutenção da competitividade no mercado, mostram-se interessadas em entender como são estruturados os processos de aprendizagem e, principalmente, aqueles relativos à transferência para os diferentes níveis da organização. Torna-se necessário entender, portanto, como ocorrem tais processos em diferentes ambientes corporativos e profissionais. Para possibilitar o estudo desses fenômenos, e necessário identificar formas de garantir a melhoria do desempenho no trabalho, investigando o processo de aquisição de conhecimentos, habilidades e atitudes (CHA's) por meio de ações de TD\&E, formação e qualificação profissional (ZERBINI, 2008).

Para Borges-Andrade (2002), TD\&E podem ser vistos como um sistema, integrado por três elementos:

1) Avaliação de necessidades;

2) Planejamento do treinamento e sua execução 
3) Avaliação do treinamento.

Complementa Borges-Andrade (2002) que do primeiro para o segundo e deste para o terceiro, os referidos elementos mantêm entre si um constante fluxo de informações e produtos, sendo que o subsistema "Avaliação de Treinamento" seria o principal responsável pelo provimento de informações que garante a retroalimentação e, portanto, o aperfeiçoamento constante do sistema. Esta avaliação pode ser definida como um processo que inclui sempre algum tipo de coleta de dados usados para se emitir um juízo de valor a respeito de um treinamento, ou um conjunto de treinamentos.

As avaliações das necessidades objetivam diagnosticar ou prognosticar necessidades de TD\&E, que são lacunas de competências ou nos repertórios de CHA's no trabalho, de modo que as mesmas, transformadas em objetivos instrucionais, facilitem o desenho de ações de aprendizagem para atendê-las (Abbad; Freitas; Pilati, 2006). De acordo com os autores, as necessidades de treinamento, compreendidas como discrepâncias ou desvios de desempenho, em termos de necessidades futuras, podem ser definidas e avaliadas nos níveis: macro (organização), no meso (grupos e equipes) e micro (indivíduos). Ainda segundo os mesmos, embora o mais comumente tratado seja o individual, tais necessidades podem decorrer de fatores extraorganizacionais, como mudanças tecnológicas, políticas, econômicas, legais, sociais e ecológicas, entre outras, que afetam a vida da organização, seus negócios e serviços.

O Planejamento de Treinamento e a execução ocorrem posteriormente ao Diagnóstico de Necessidades de Treinamento. Segundo Canabrava e Vieira (2006), com a seleção das necessidades indicadas, inicia-se tal fase, que é destinada à consolidação das atividades de treinamento levantadas e das prioridades de atendimento. Nesse momento são definidas as estratégias de implementação, incluindo a análise da consistência das informações e, se for o caso, poderá haver uma reavaliação das indicações das necessidades com os gerentes da instituição, para fundamentação dos aspectos que foram indicados durante o diagnóstico.

No planejamento sistemático do ensino, os eventos instrucionais tornam-se instrumentos úteis para ativar, manter, melhorar ou facilitar os processos cognitivos envolvidos na aprendizagem. Sua utilização adequada transforma-se num método eficiente para a aquisição dos CHA's esperado. (ABBAD; BORGES-ANDRADE, 
2004). Abbad et. al (2006) especifica que o plano instrucional deverá conter descrição dos procedimentos, recursos, meios instrucionais e cargas horárias estimadas de aplicação.

A realização das etapas do desenho instrucional compreende desde a redação dos objetivos instrucionais e escolha da modalidade de entrega da instrução, até o teste do plano ou desenho instrucional, para posterior execução de todo o planejamento descrito, o qual corresponde à etapa preponderante para o funcionamento com excelência dos sistemas de TD\&E.

Por fim, dentre os subsistemas de TD\&E, conceitua-se Avaliação de Treinamento como sendo instrumento fundamental que propicia o aprimoramento constante dos programas de treinamento, a fim de garantir efetividade do sistema de TD\&E. Ressalta-se que o referido subsistema será abordado mais detalhadamente no próximo subitem.

\subsection{Avaliação de Treinamento}

Avaliar treinamento é uma prática que já ocorre há algumas décadas, sempre tendo seus moldes aperfeiçoados. Entre os modelos clássicos de avaliação estão os propostos por Kirkpatrick (1976) e Hamblin (1978).

De acordo com Freitas e Borges-Andrade (2004), o modelo proposto por Kirkpartrick (1976), define quatro níveis de avaliação: reação, aprendizagem, comportamento no cargo e resultados. Kirkpatrick (1976) sugere que o modelo proposto por ele apresenta níveis de avaliação seqüenciais, lineares e fortemente correlacionados entre si. As reações representam medidas de satisfação com o treinamento em termos de qualidade do programa, instalações e desempenho do instrutor. A aprendizagem diz respeito à avaliação das diferenças de desempenho dos treinandos antes e depois do treinamento, em termos dos objetivos instrucionais. O comportamento no cargo aborda as melhorias no desempenho do treinando no trabalho, decorrentes da aplicação do que foi aprendido no treinamento. Os resultados enfocam as mudanças ocorridas no nível da organização em função do treinamento. 
Hamblin (1978) adaptou o modelo de Kirkpatrick, propondo que uma avaliação de treinamento deveria seguir cinco níveis:

1) Reação, que levanta atitudes e opiniões dos treinandos sobre os diversos aspectos do treinamento, ou sua satisfação com o mesmo;

2) Aprendizagem, que verifica se ocorreram diferenças entre o que os treinandos sabiam antes e depois do treinamento, ou se os seus objetivos instrucionais foram alcançados;

3) Comportamento no cargo, que leva em conta o desempenho dos indivíduos antes e depois do treinamento, ou se houve transferência para o trabalho efetivamente realizado;

4) Organização, que toma como critério de avaliação o funcionamento da organização, ou mudanças que nela possam ter ocorrido em decorrência do treinamento;

5) Valor final, que tem como foco a produção ou o serviço prestado pela organização, o que geralmente implica em comparar custos do treinamento com os seus benefícios.

Embora os modelos supracitados sejam referência e ainda bastante utilizados, pesquisas mais recentes sugerem outros fatores a exercer influência na efetividade do treinamento, como explicita o Modelo de Avaliação Integrado e Somativo (MAIS), proposto por Borges-Andrade (1982), estabelecendo cinco fatores básicos: insumos, procedimentos, processo, resultados e ambiente; e posteriormente ao Modelo MAIS, desenvolveu-se o Modelo de Avaliação utilizado para a realização da presente pesquisa, que é o proposto por Abbad (1999) - o Modelo Integrado de Avaliação do Impacto do Treinamento no Trabalho (IMPACT) -, que mensura o suporte organizacional, características do treinamento, características da clientela, níveis de avaliação de reação, aprendizagem, suporte à transferência e impacto e investiga diversas variáveis preditivas de eficiência e eficácia do treinamento. Cabe ressaltar que os seis componentes explicitados são determinantes no impacto do treinamento no trabalho.

Como o presente trabalho se pautou na Avaliação de Reação para coleta de dados e posterior análise dos resultados, fazendo uma descrição da "Avaliação de Reação ao Treinamento" utilizada para a presente pesquisa, baseada no Modelo 
IMPACT, adotou-se os componentes "Características da Clientela", "Programação", "Aplicabilidade", "Resultados" e "Desempenho Didático do Instrutor". Cabe mencionar que Reação, conforme entendimento de Lacerda e Abbad (2003), é compreendida como o nível de satisfação dos participantes com a programação, o apoio ao desenvolvimento do curso, a aplicabilidade, a utilidade e os resultados do treinamento.

Segundo Abbad (1999), Características da Clientela (...) é definido, no IMPACT, como o conjunto de informações demográficas, funcionais, motivacionais e atitudinais relativas aos participantes dos treinamentos estudados. Os itens concernentes à Programação compreendem a opinião do participante do treinamento acerca da qualidade do treinamento, em termos de clareza da definição de objetivos, compatibilidade dos objetivos com as necessidades de treinamento, carga horária (diária e total) e orientação e adequação do conteúdo programático aos objetivos do curso.

Ainda de acordo com Abbad (1999), o conjunto de variáveis denominado Aplicabilidade e Utilidade do Treinamento representa a opinião do participante do treinamento sobre o valor instrumental do mesmo na resolução de problemas de trabalho, a possibilidade de aplicação, no trabalho, dos conhecimentos adquiridos no treinamento, assim como a conveniência da disseminação do treinamento para outros servidores. Quanto aos itens relacionados aos Resultados, tem-se que estes se referem à opinião do participante acerca da efetividade do curso, em termos do quanto capaz de produzir assimilação de conhecimentos, capacitação para o reconhecimento de situações onde é correto aplicar os novos conhecimentos. Além disso, no instrumento de coleta de dados, constam itens acerca do estímulo dado pelo treinamento ao participante para aplicar, no trabalho, os conhecimentos recémaprendidos. E por fim, Desempenho Didático, o qual se relaciona às avaliações feitas pelos participantes do treinamento acerca da qualidade dos procedimentos e processos instrucionais adotados pelo instrutor em sala de aula, dentre os quais: transmissão de objetivos, sumarização e revisão dos temas, nível de profundidade com que os assuntos foram abordados, ritmo de apresentação, uso de estratégias motivacionais, qualidade da apresentação dos conteúdos e exemplos, uso de estratégias (...).

Abbad (2006) explicita que questões empíricas relevantes na área de avaliação de treinamento, desenvolvimento e educação de pessoas (TD\&E) são 
aquelas que tentam identificar as condições necessárias e/ou suficientes para que um desempenho aprendido em um treinamento seja aplicado de forma eficaz e inteligente no ambiente de trabalho. Para a autora, as pesquisas exploratórias sobre transferência de treinamento devem fundamentar investigações empíricas em um modelo que incluísse condições ambientais, características do treinamento e da clientela, visando à identificação das condições necessárias à aplicação eficaz do aprendido em treinamento no ambiente de trabalho. Infere-se que a Avaliação proposta pela mesma autora em 1999 - Modelo IMPACT - abrange tais componentes, e corrobora para o fato de as avaliações de treinamento ser um suporte para a obtenção de dados para o melhoramento de todo o processo de TD\&E nas organizações.

Impende evidenciar que alguns, dentre os indicadores existentes na Avaliação proposta, são importantes determinantes dos resultados de treinamentos, dentre as quais, as características individuais dos treinandos, a motivação para treinar ou Motivação para aprender e a instrumentalidade do treinamento.

Abbad (1999) descreve que a linha de pesquisa sobre a clientela caracteriza-se por investigar o relacionamento entre as características pessoais (demográficas, cognitivas, afetivas, motivacionais) e a eficácia de eventos instrucionais, em termos de aprendizagem, reação e transferência.

Já Motivação para treinar ou Motivação para aprender pode ser definida como direção, esforço, intensidade e persistência como que os treinandos se engajam nas atividades orientadas para aprendizagens antes, durante e depois do treinamento (Lacerda; Abbad, 2003). Segundo as autoras, há ainda outro estado afetivo presente ao final do treinamento que merece atenção: a extensão na qual os indivíduos estão motivados para aplicar o conteúdo que aprenderam. O objetivo principal de muitos cursos é aumentar a disposição dos participantes para usar, no trabalho, o material visto no programa, o que é denominado Motivação para Transferir. E ainda na visão de Lacerda e Abbad (2003), caracterizando Instrumentalidade, tem-se que esta diz respeito à estimativa de que determinado desempenho seja um caminho adequado para chegar a uma recompensa. 


\subsection{TD\&E na Esfera Pública}

Apesar de as bases teóricas da área de TD\&E serem, na sua grande maioria pautadas nas experiências das empresas privadas, evidencia-se o fato de muitas publicações a respeito do assunto, principalmente as nacionais, terem como objeto de estudo os órgãos e instituições públicos, como é o caso de instituições como Embrapa, Petrobrás e TCU. Pressupõe-se, então, que muito do que tem sido constatado deveria ser aplicado, à risca, à realidade do Ente Estatal; contudo, a dinâmica de aplicabilidade dos preceitos teóricos (validados cientificamente) junto às instituições públicas não se dá de forma tão simples, ao contrário do que as entidades privadas vem perpetrando, fazendo com que haja avanços mais precocemente no sentido de investir na promoção da TD\&E junto aos colaboradores que nas instituições públicas.

As organizações públicas possuem alguns entraves para a promoção da TD\&E, como o fato de ficarem dependentes de legislação que autorize suas atividades; o repasse de verbas públicas precisa estar expressamente destinado para investimento com pessoal; parcerias com entidades públicas de outras esferas que permitam economia de gastos, ao invés de se buscar cursos por meio de entidades privadas; licitações (ou dispensa delas) para a contratação de empresas/cursos para os servidores, entre outras medidas.

Para garantir as ações de TD\&E para os servidores públicos, foi feita a inserção da Emenda Constitucional no. 19 (1998), conforme expresso no Art. 39 do texto Constitucional, introduzindo a determinação para que a União, os Estados Federados e o Distrito Federal mantivessem as Escolas de Governo para a formação e o aperfeiçoamento dos agentes públicos, conforme sobrescrito abaixo. Ressalta-se o fato de se tratar de um grande avanço para os órgãos e entidades públicas tal previsão legal, especificando a obrigação dos Governos em manter financeiramente - as instituições públicas responsáveis pela efetivação das ações de TD\&E.

Art. 39. A União, os Estados, o Distrito Federal e os Municípios instituirão conselho de política de administração e remuneração de pessoal, integrado por servidores designados pelos respectivos Poderes. 
$\S 2^{\circ}$ A União, os Estados e o Distrito Federal manterão escolas de governo para a formação e o aperfeiçoamento dos servidores públicos, constituindo-se a participação nos cursos um dos requisitos para a promoção na carreira, facultada, para isso, a celebração de convênios ou contratos entre os entes federados.

Diversas Escolas de Governo (federais, estaduais e municipais) foram instituídas com o intuito de ampliar a capacidade do governo e trazem em seu cerne uma concepção integradora e holística, que se resume na formação instrumental, crítica e política dos servidores públicos. Para tal, tais instituições tendem a contemplar estratégias de capacitação que possibilitem o constante aprimoramento das competências para o trabalho, a fim de que tanto os novos servidores a serem contratados como os já em exercício tenham o perfil desejado de cada cargo e/ou função, para atender aos novos desafios do setor público.

Vendo pelo prisma da Administração Pública local - Distrito Federal -, cabe descrever um pouco de sua história em termos das ações de TD\&E, visto que este trabalho tem como organização escolhida a Escola de Governo do Distrito Federal, instituição que oferece cursos de capacitação e desenvolvimento aos servidores públicos do Ente Estatal Distrital. O TD\&E ocorre no âmbito Administração local desde o surgimento da máquina administrativa no âmbito do Distrito Federal, que se deu em 1960, com a inauguração de Brasília, sempre houve preocupação por parte do Governo local em investir em capacitação para os servidores. Em 1961, Brasília crescia e atraía pessoas que vinham de diversas regiões do País em busca de oportunidades que a nova capital oferecia. Essas pessoas não possuíam preparo técnico para o desempenho das atividades exigidas pela Prefeitura do Distrito Federal - PDF. Para atender às demandas de qualificação dos primeiros servidores da PDF, o Prefeito Paulo de Tarso assinou o Decreto ํ․ 43, de 28 de Março de 1961, criando o Serviço de Seleção e Aperfeiçoamento - SSA, posicionando-o na Secretaria-Geral de Administração - SGA, surgindo, assim, o quadro de servidores da Prefeitura do Distrito Federal - PDF. (OLIVEIRA; LIMA, 1999). Em 1966, para suprir as necessidades da Administração quanto ao atendimento de clientela mais ampla e ao desenvolvimento das atividades mais complexas e diversificadas, o Prefeito Plínio dos Reis Cantanhede de Almeida assinou o Decreto №. 511, de 24 de Julho de 1966, criando o Centro de Seleção e Treinamento CEST. (OLIVEIRA; LIMA, 1999). Já em 1975, apesar de todas as alterações 
ocorridas em relação à estrutura e às competências do CEST, foi verificada a necessidade de mudança ainda mais significativa. Desta forma, o Governador Elmo Serejo de Farias assinou o Decreto no. 3.121, de 31 de Dezembro de 1975, que alterava a denominação do Centro de Seleção e Treinamento - CEST para Instituto de Desenvolvimento de Recursos Humanos - IDR e definia a relativa autonomia do novo Órgão. (OLIVEIRA; LIMA, 1999). O IDR, vinculado à Secretaria de Administração do Distrito Federal (SEA), baseava seu trabalho na crença da potencialidade de transformação existente em cada indivíduo, no grupo e na organização.

Partindo para o ano 2000, tem-se que para se adequar de forma efetiva às crescentes demandas da Administração Pública, a recém-criada Secretaria de Gestão Administrativa (SGA) passa a ter nova estrutura por meio do Decreto no. 21.599, de 5 de Outubro de 2000. O IDR é extinto e surge a Escola de Governo do Distrito Federal - EGDF. No mesmo ano, foram realizados vários projetos na área de TD\&E. O mais significativo deles foi a publicação do Plano de Capacitação e Desenvolvimento dos Servidores do Distrito Federal, instituído pela Portaria SGA no. 262, de 14 de maio de 2001, que norteou por vários anos as ações de TD\&E no âmbito de toda a Administração Pública do Distrito Federal. Em 2004, entre um conjunto de ações com o objetivo de promover a modernização da administração pública do Distrito Federal e, também, em busca de melhor atendimento na prestação de serviços à sociedade, a Secretaria de Gestão Administrativa (SGA), dentro de nova estrutura, cria a Escola de Gestão Pública - EGEP, por meio do Decreto no. 24.392, de 27 de Janeiro de 2004. (OLIVEIRA; LIMA, 1999). Em 2007, na continuidade das ações traçadas e considerando a necessidade de racionalização da estrutura administrativa do Governo do Distrito Federal, conforme - Plano de Governo da gestão que assumiria naquele ano, criou-se por meio do Decreto no. 27.591, de 01 de Janeiro de 2007, a Secretaria de Planejamento e Gestão - SEPLAG e a atual Escola de Governo do Distrito Federal (EGOV), órgão de comando e supervisão, diretamente vinculado à SEPLAG, com a função promover ações de capacitação e desenvolvimento dos servidores do GDF.

Adentrando uma realidade mais próxima, após um vasto clamor por parte das áreas de Gestão de Pessoas da Administração Pública Distrital, houve o lançamento do Decreto Distrital n. 29.814/2008, no qual foi instituída a Política de Gestão de Pessoas do Governo do Distrito Federal e propostas várias mudanças 
organizacionais e político-sociais para tal Ente Estatal. Contudo, o que faltava para privilegiar a todos os servidores era um documento mais específico que tratasse do TD\&E para todos os servidores distritais. Para tanto, publicou-se o Decreto $\mathrm{n}^{\circ}$. 31.453, de 22 de Março de 2010 - a Política de Capacitação e Desenvolvimento para os servidores da Administração Direta, Autárquica e Fundacional do Distrito Federal. Trata-se de um marco legal de grande importância por assegurar a toda a população de servidores a possibilidade de participarem e se envolverem com o processo de capacitação, importante tanto para o desenvolvimento pessoal, como para o institucional. A capacitação, nos termos do referido Decreto, tem como principais finalidades:

1) Contribuir para a implantação dos projetos estratégicos do governo;

2) Promover o desenvolvimento de competências necessárias ao alcance da missão institucional dos diversos órgãos e unidades;

3) Criar possibilidades de qualificação dos servidores efetivos para a promoção funcional nas carreiras públicas, bem como para o exercício de atividades de direção e assessoramento;

4) Criar oportunidades para a melhoria dos processos de trabalho e de desempenho profissional, com foco em resultados.

E quanto ao desenvolvimento de pessoas, a finalidade é atingir resultados que ultrapassem os limites da própria valorização e do desenvolvimento pessoal do servidor, destacando os aspectos abaixo:

1) Ampliação dos pontos de contato entre a Administração Pública e a sociedade, a partir da postura ética, responsável, comprometida e eficiente do servidor;

2) Contribuir para a formação de uma cultura que perceba o servidor como agente de desenvolvimento do Distrito Federal;

3) Incluem-se como ações de desenvolvimento os eventos que visem à melhoria da qualidade de vida e do relacionamento interpessoal no ambiente de trabalho, ao voluntariado, à participação em projetos de responsabilidade sócio-ambiental e ao fortalecimento da democracia, da 
justiça, da cidadania, da inclusão social, da defesa da ética e da universalização dos direitos.

Contanto, ressalta-se que independente de quaisquer iniciativas por parte do Ente Público na promoção do TD\&E junto aos servidores, é necessária, principalmente, a predisposição por parte dos agentes públicos para lidar com novos desafios em sua atuação profissional, fazendo-se necessária a observação de seu comportamento atual, assim como de suas respectivas chefias imediatas, no sentido de incentivar seus colaboradores a participarem do TD\&E em prol de suas unidades de trabalho e para seu desenvolvimento pessoal e cidadão. 


\section{MÉTODOS E TÉCNICAS DE PESQUISA}

A Avaliação de Reação ao Treinamento realizada junto aos servidores participantes do curso amostral de "Gestão de Documentos", promovido pela EGOV, foi diagnosticado através da utilização de procedimento de coleta de dados junto à população participante do Treinamento no período de 06 a 10 de Dezembro de 2010.

Tem-se que a pesquisa com a população de alunos-servidores ocorreu em dois momentos que esta foi submetida ao Treinamento promovido pela EGOV, conforme descrito oportunamente, a fim de avaliar o perfil sócio demográfico e profissional da população em questão e variáveis de reação percebidas positivamente no treinamento promovido pela EGOV e as percebidas negativamente no - fazendo uma correlação entre as variáveis: treinamento $x$ variáveis positivas $x$ variáveis negativas. Constitui variável independente o treinamento (curso realizado na EGOV), enquanto que a variáveis dependente são: programação, aplicabilidade e utilidade do treinamento, resultados, desempenho do instrutor - todas provenientes da pesquisa aplicada junto à população analisada. Ressalta-se 0 fato de haver também variáveis-controle, tais como características pessoais (sexo, idade, escolaridade) e profissionais (cargo).

Para classificar o tipo de pesquisa implementada neste Trabalho, tomou-se como referência o critério de classificação proposto por Vergara (2009):

1) Quanto à natureza, classifica-se a pesquisa quantitativa, por mensurar em números os dados analisados junto à população em questão.

2) Quanto aos fins, tem-se a referida pesquisa como descritiva, pois a mesma irá expôr características de determinada população ou fenômeno.

3) Quanto aos meios, identificou-se a seguinte tipologia: Pesquisa de Campo, pois será realizada investigação empírica no local onde irá ocorrer o fenômeno (treinamento) e, também, que disporá de elementos para explicá-lo. 


\subsection{Caracterização da Instituição}

A Escola de Governo do Distrito Federal (EGOV) é a unidade da Secretaria de Estado de Planejamento, Orçamento e Gestão do Distrito Federal (SEPLAG/DF) que tem por competência promover ações de capacitação e desenvolvimento dos servidores públicos da Administração Pública do Distrito Federal. Tem como missão fortalecer as instituições do Governo local, objetivando a melhoria contínua dos serviços públicos e do atendimento ao cidadão, desenvolvendo competências gerenciais, técnicas e comportamentais por meio de cursos de capacitação e treinamento, mas seguintes modalidades: presencial, semipresencial e à distância.

Além da realização de cursos de especialização, aperfeiçoamento e atualização; fóruns de debates; seminários nacionais e internacionais; diálogos intersetoriais; ciclos de palestras, entre outros; a EGOV possui a expertise de acompanhar e avaliar cursos e eventos, com o objetivo de aperfeiçoar os projetos desenvolvidos e melhorá-los para seu público alvo - os servidores.

Localizada no Setor de Garagens Oficiais Norte (SGON), Área Especial no 01, Quadra 01 - próxima ao Edifício Anexo ao Palácio do Buriti, a Escola de Governo do Distrito Federal ocupa área de aproximadamente $3.432 \mathrm{~m}^{2}$ e tem a seguinte estrutura física, devidamente equipada:

1) 05 (cinco) salas de aula para 45 pessoas;

2) 05 (cinco) salas de aula para 30 pessoas;

3) 01 (uma) sala multifuncional para 50 pessoas;

4) 01 (um) miniauditório para 60 pessoas;

5) 01 (um) auditório com capacidade para 135 pessoas;

6) 01 (um) laboratório de informática para atender 40 pessoas;

7) 01 (uma) sala de videoconferência;

8) Amplo estacionamento. 


\subsection{População e amostra ou participantes do estudo}

Definiu-se como amostra a ser analisada e trabalhada 01 (uma) turma de 33 (trinta e três) servidores, dos mais diversos cargos, idades, perfis e lotações, todos servidores de carreira da Administração Pública do Distrito Federal, que foi formada com a finalidade da promoção da capacitação em "Gestão de Documentos" pela Escola de Governo do Distrito Federal (EGOV).

Estabeleceu-se como critério para participação neste curso, além da préinscrição junto ao sistema eletrônico da EGOV para captação de solicitações de participação em cursos (que ocorre via Internet, por meio de preenchimento de ficha de inscrição on-line), a seleção dos servidores pelo Interlocutor da Unidade no qual os mesmo são lotados, pois se trata de procedimento padrão que precisa ser executado por quem está pleiteando a vaga no curso, haja vista que o Interlocutor da Unidade é o responsável por organizar turmas e monitorar todo o processo de disponibilização de treinamentos para órgão ao qual este representa, verificando os servidores que trabalhavam na área de Gestão Documental, Arquivamento ou que apresentavam necessidade de tais conhecimentos a serem oferecidos pelo referido treinamento por conta de demanda setorial.

Cabe explicitar que supracitado evento apresenta carga horária de 20 horas/aula e tem por finalidade orientar a organização documental dos órgãos do GDF; divulgar a Legislação Arquivística vigente no GDF; assim como explicitar a aplicabilidade das técnicas de gestão documental, conservação e organização documental.

\subsection{Caracterização dos instrumentos de pesquisa}

Os instrumentos de pesquisa utilizados para a aquisição de material para a análise da população elencada este Projeto são 02 (dois) questionários: o primeiro é o "Questionário Sócio-Demográfico e Profissional", construído com o objetivo de identificar dados sociais, demográficos e institucionais dos servidores em questão, o qual foi aplicado antes do início do período de Treinamento em que a população em análise foi submetida, e o segundo é uma versão reduzida do modelo de "Avaliação 
de Reação ao Treinamento", contendo uma quantidade menor do total de itens em relação ao original presente no Modelo IMPACT, tendo sido este desenvolvido e validado cientificamente por Abbad (1999), utilizado em diversas pesquisas e teses desenvolvidas por professores e estudantes do Instituto de Psicologia da Universidade de Brasília.

O primeiro questionário é composto por 07 (sete) questões de caráter sóciodemográfico e profissional, mediante o qual se obteve características como idade, sexo, cargo, nível de escolaridade, necessidade de capacitação, entre outros, da população analisada.

Já o segundo foi utilizado nesta pesquisa como Instrumento de Coleta de Dados para se realizar a avaliação da Reação ao Treinamento junto aos servidores estudados. Foram elencadas 18 (doze) questões do questionário Original validado por Abbad (1999), sobre as quais os participantes do Treinamento marcaram numa escala que apresenta os indicadores - Ótimo, Muito Bom, Bom, Regular, Ruim e Não se aplica - com a finalidade de avaliar a efetividade, a aplicabilidade do treinamento realizado para a melhoria do desempenho organizacional do servidor, as oportunidades de se colocar em prática os ensinamentos adquiridos e avaliação do suporte instrucional. Impende mencionar que tal instrumento, com respostas em escala ordinal, qualifica os itens de avaliação de reação, que estão agrupados em indicadores. Os indicadores de treinamento presencial são classificados em Programação do Treinamento, Aplicabilidade e Utilidade do Treinamento, Resultado do Treinamento, Desempenho Didático (Instrutor) e, também, Campo de Observações, o qual permite ao aluno escrever suas considerações, caso existam ou deseje expressá-las.

\subsection{Procedimentos de coleta e de análise de dados}

O procedimento de coleta de dados aconteceu em dois momentos distintos e teve como única responsável pela aplicação de questionários - a autora desta pesquisa.

Relatando sequencialmente quais foram os procedimentos preparatórios para a devida coleta de dados, tem-se que, em princípio, a pesquisadora verificou 
com o Interlocutor de sua unidade de lotação quais seriam os cursos que seriam realizados próximo ao período hábil para a realização da referida pesquisa presencial, a fim de subsidiar o trabalho em questão, conforme havia sido vislumbrado no Projeto de Pesquisa (semestre anterior).

Após tal feedback (do Interlocutor) e definidas as possibilidades existentes para o presente trabalho, optou-se pelo curso de "Gestão de Documentos", pelo fato de este apresentar composição de alunos bastante plural (esta noção do "tipo de população participante" existe por parte dos Interlocutores das Unidades Administrativas dos órgãos pelo fato de este ser um curso rotineiramente ofertado). Foi realizado um contato prévio por este Interlocutor (que gentilmente se predispôs a colaborar com a efetivação da pesquisa) com a Secretaria de Cursos (SECUR/EGOV/SEPLAG), para ser verificada a possibilidade de participação da pesquisadora no referido curso. Para tanto, foi enviado por fax ao mencionado setor (SECUR) a Carta de Apresentação para a Instituição, constante no "Apêndice A" deste trabalho, para formalização do pedido de participação no treinamento em questão.

Após liberada a visita para a coleta de dados, com a anuência da SECUR, que organiza e promove todos os cursos ofertados pela Escola de Governo (EGOV), os quais devem obedecer ao Plano de Capacitação Anual, que é divulgado oportunamente via Diário Oficial do Distrito Federal pela SEPLAG (no exercício atual a Grade de Eventos de Capacitação - ou Plano de Capacitação 2010 - foi divulgada por meio da Portaria no. 337, de 15 de Dezembro de 2009, publicada no Diário Oficial do Distrito Federal n‥ 248, de 24 de dezembro de 2009, Seção 1, página 26), iniciou-se o procedimento de coleta de dados para este trabalho (primeira etapa), na forma de aplicação presencial de questionários junto à população elencada para tal pesquisa, no terceiro dia do treinamento em "Gestão de Documentos" - 08 de Dezembro de 2010.

Neste dia, 08 de Dezembro de 2010, foi apresentada a Carta de Apresentação para os participantes, a qual continha dados da pesquisadora e explicação da pesquisa, e aplicado o "Questionário Sócio-Demográfico e Profissional" aos 33 (trinta e três) treinandos selecionados e efetivos do curso. Tal procedimento levou cerca de 03 (três) minutos e ocorreu antes do intervalo para o coffee-break (por volta de $10 \mathrm{~h}$ da manhã). 
Já a segunda etapa da referida coleta de dados se deu no dia 10 de Dezembro de 2010, último dia do treinamento em questão, ocorrendo próximo ao término da aula, a fim de averiguar junto aos partícipes sua impressão a respeito do treinamento ao qual estavam sendo submetidos no âmbito pessoal, laboral e em termos de conhecimento.

Findo o processo aplicatório de questionários, foram realizadas análises estatísticas exploratórias e descritivas do material coletado, a fim de identificar o perfil dos alunos e sua percepção do curso e sua importância para os mesmos. Num primeiro momento, todos os dados provenientes dos questionários foram repassados para uma planilha do Excel (arquivo eletrônico), onde foram realizados cálculos da média, desvio padrão dos dados e moda (no caso do Questionário de Reação ao Treinamento) e moda e média (quanto ao Questionário Sócio Demográfico e Profissional).

Por conseguinte, estabeleceu-se como parâmetro para a devida mensuração, análise e demonstração dos dados coletados no primeiro questionário o uso do modelo percentual, com ilustração em gráficos de pizza, a fim de proporcionar melhor visualização diferencial das possíveis respostas aos itens do questionário, de caráter descritivo, do perfil da amostra, enquanto que para o segundo adotou-se a análise estatística aplicada na elaboração tabular dos dados obtidos - a média e desvio padrão. 


\section{RESULTADOS E DISCUSSÃO}

Os resultados obtidos através da pesquisa presencial de caráter exploratório e analítico a respeito da população de 33 (trinta e três) servidores-alunos do curso de "Gestão de Documentos" são explicitados nesta seção através de demonstração gráfica e discussão dos resultados obtidos.

Quanto ao Perfil sócio-demográfico e profissional da amostra analisada, mensurado através do Questionário "Sócio-Demográfico e Profissional" devidamente aplicado junto à população amostral no terceiro dia do curso "Gestão de Documentos", tem-se que 21\% - 07 participantes - eram alunos do sexo masculino, e 79\% - o que corresponde a 26 alunas - eram do sexo feminino, o que corrobora para a inferência de um desequilíbrio na participação dos gêneros em curso de capacitação, pendendo para o sexo feminino em detrimento do outro, conforme pode ser visto na Figura 02. Não é possível concluir uma predominância participativa das servidoras nos cursos de capacitação em relação aos servidores (homens), haja vista o tamanho da amostra ser pequeno em relação à população treinanda geral anual. Cabe mencionar que através da Consultoria Interna do Sistema de Gestão de Pessoal (SIGEP) do ano passado, constatou-se que o quantitativo de servidores do GDF apresentava igualdade em termos quantitativos, pairando a casa dos $50 \%$ para cada sexo (feminino e masculino), o que demonstra um equilíbrio quantitativo entre os sexos na população de servidores.

Figura 02: Gráfico do Sexo (gênero) dos treinandos.

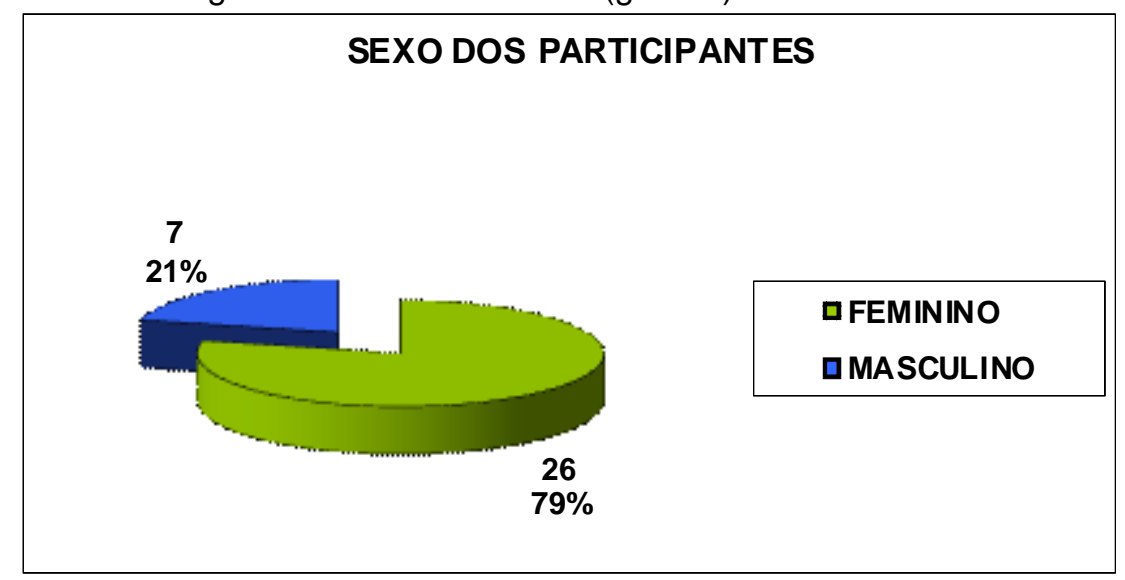


Relativo à faixa etária, percebe-se uma predominância de servidoresparticipantes do treinamento com idades entre 41 e 50 anos, correspondendo a $37 \%$ do total de alunos, conforme pode ser visto na Figura 03.

Figura 03: Gráfico da Faixa Etária dos treinandos

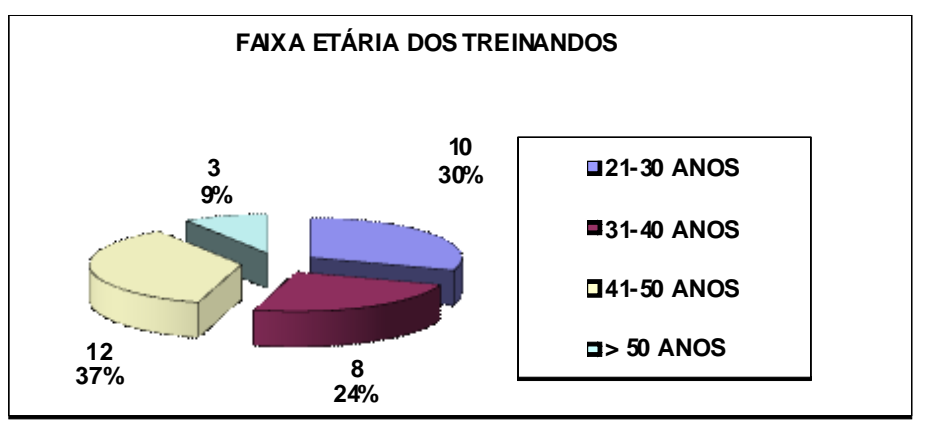

A leve preponderância por alunos pertencentes à faixa etária dos 41-50 anos se deve ao fato de ser numerosa a população de servidores que ingressaram na Administração Pública por volta dos anos 90, época da qual provêm a grande leva de servidores dos quadros de pessoal do Distrito Federal. Contudo, em crescimento nos últimos anos, haja vista o concurso ocorrido em 2004 (Edital 01/2004 SGA/GDF), após 15 anos sem haver a realização de certames com este objetivo selecionatório, por meio do qual houve a aprovação de candidatos das mais diversas faixas etárias, principalmente de adultos entre 25 e 35 anos, segundo Consultoria Interna do SIGEP (2009). Tal informação corrobora o fato de significativa parte da população que precisa se qualificar para fins laborais (como é o caso amostra utilizada para este trabalho), e que está participando de treinamentos, pertencer à faixa etária supracitada - 24\% (ou seja, 8 dos 33 participantes pertencem à faixa etária até 30 anos). Cabe ressaltar que as categorias etárias dos 21-30 e dos 31-40, somando seus percentuais, sobrepassam a maioria dos participantes, o que corresponde a $54 \%$ dos entrevistados.

Com relação aos cargos ocupados pelos servidores em questão, tem-se que formam elencados, dentre os existentes na estrutura de cargos da Carreira de Administração Pública, da qual advêm à maioria dos participantes dos cursos de capacitação ofertados pela Escola de Governo, segundo Consultoria Interna do SIGEP (2009). As possíveis alternativas: Auxiliar (nível fundamental), Técnico (nível médio), Analista (nível superior) e Outros (cargos em comissão e outros cargos da 
Estrutura do Governo do Distrito Federal - dos mais diversos níveis de escolaridade). Houve um empate técnico entre os cargos de Técnico - nível médio - $42 \%$ dos servidores - e Outros - também com o mesmo percentual. Trata-se de um reflexo da estrutura de cargos e salários da Administração Pública como um todo, que por possuir mais atribuições que exijam servidores com cargos deste nível de escolaridade (normalmente são esses tipos de servidores trabalham nas áreas-fim e operacional dos órgãos públicos). Evidencia-se a disposição dos cargos ocupados pelos participantes do curso na figura abaixo (Figura 04).

Figura 04: Gráfico dos cargos dos treinandos.

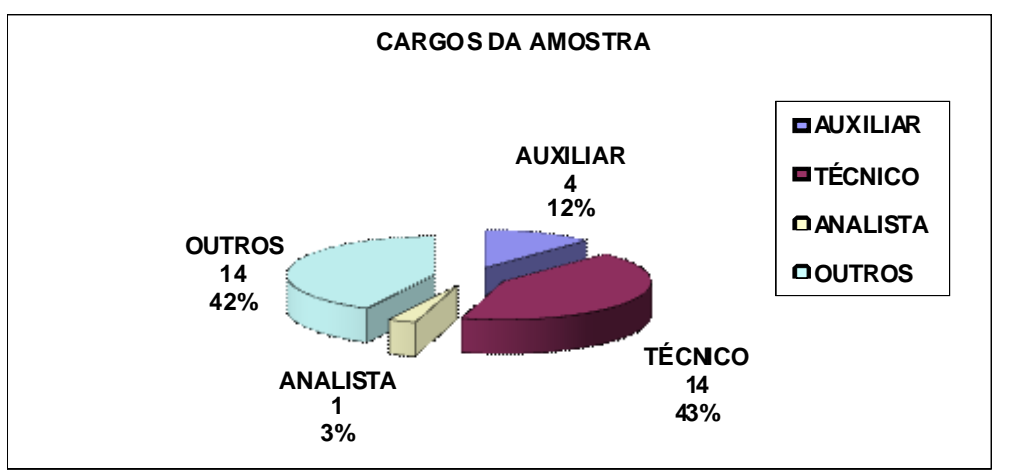

Os cargos de Analista e Auxiliar correspondem a $11 \%$ do quantitativo da amostra, sendo apenas 01 Analista e 04 Auxiliares. Evidencia-se o fato de o cargo de Auxiliar estar em processo de extinção, segundo informações obtidas por meio de Dirigentes do órgão em questão, haja vista não haver interesse da Administração Pública nos últimos 10 (dez) anos em promover seleções para o ingresso de agentes públicos apenas com o nível fundamental de escolaridade, visto que com a mudança no panorama escolar da população nesta última década e, também, em virtude das exigências do mercado de trabalho (globalização, explosão das telecomunicações, gestão do conhecimento, panorama político-econômico instável) e da importância da Educação, como proposto por Canabrava e Vieira (2006), "um processo de construção ativa do conhecimento, cultura, valores, crenças, aptidões, por meio da qual se desenvolve um indivíduo participativo, compromissado e transformador", tornou-se inevitável para a população ter que se qualificar e estudar 
mais anos do que há três ou quatro décadas (anos 60 e 70), o que justifica a situação funcional da amostra elencada para este estudo.

Quanto à escolaridade, foi constatado que 64\% dos servidores treinandos possuem nível superior (são graduados), apesar de muitos destes serem provenientes de cargos de nível médio e fundamental. Tais dados sugerem a preocupação da maioria dos servidores em progredir em termos de conhecimento, não permanecendo (estagnação) ao nível escolar que os propiciou o ingresso ao cargo público, perante o qual estão investidos por meio de concurso público excetua-se da condição de serem concursados os servidores que ingressaram há mais de 20 anos e não foram submetidos a este mecanismo de seleção para adentrar a Administração Estatal como agentes públicos, representantes do Distrito Federal perante a comunidade.

Conforme expresso no Gráfico a seguir (Figura 05), vislumbra-se a presença modesta - apenas 3\% - o que corresponde a 01 servidor na amostra - de participantes que ainda não fizeram ou não completaram o ensino fundamental, o que configura um inexpressivo quantitativo frente aos $97 \%$ de servidores que possuem nível médio e superior.

Figura 05: Gráfico dos níveis de escolaridade dos treinandos.

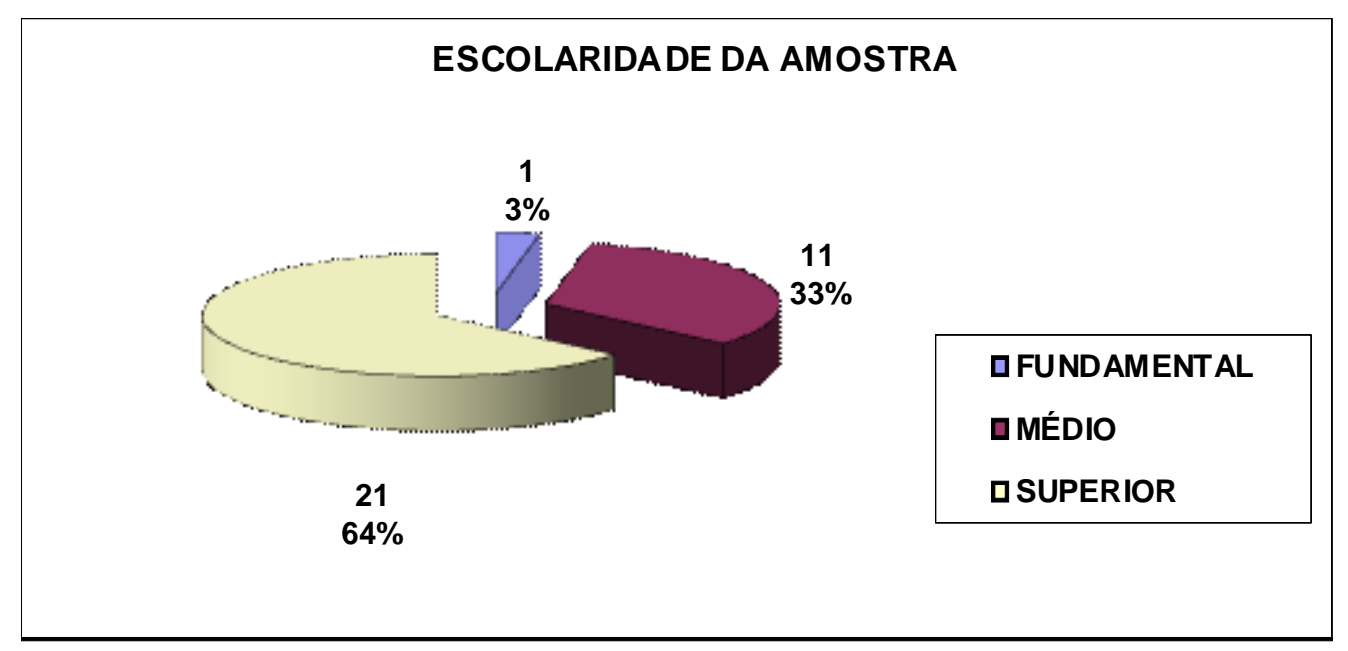

Por meio do "Questionário Sócio Demográfico e Profissional”, foi perguntado aos treinandos qual era seu tempo de serviço no cargo público, os quais exercem junto à Administração Pública do Distrito Federal, e obteve-se a média de 7,5 anos de serviços prestados ao Ente Público Distrital, sendo que o menor valor foi 0 (menos de um ano) ano, e o maior 27 (vinte e sete) anos. Especificamente no caso 
deste item do questionário, obteve-se o maior quantitativo (moda) de resposta quanto ao tempo de serviço o valor 0 (menos de um ano de serviço), o que corrobora para se compreender a preocupação das Chefias e das Unidades em treinar os servidores com ingresso mais recente nos órgãos.

Partindo para as questões de opinião do "Questionário Sócio Demográfico e Profissional", iniciamos com a que se refere aos fatores motivacionais para a participação em treinamentos. A população em questão, dentre as opções sugeridas no questionário aplicado, poderia responder como motivador para sua participação no treinamento "os novos conhecimento a serem adquiridos" "pedido da chefia", "vantagem pecuniária" (Gratificação de alguma espécie por realização de cursos). Houve uma quase unanimidade nas respostas, apontando como principal motivador que colabora para a participação de tais servidores em cursos de capacitação a aquisição de novos conhecimentos, correspondendo a $91 \%$ das respostas - ou seja, 30 dos 33 participantes do curso declararam entender que este era o principal motivo pelo qual participam de treinamentos, de acordo com o expresso no Gráfico subseqüente (Figura 06).

Figura 06 Gráfico dos níveis elementos motivacionais dos treinandos.

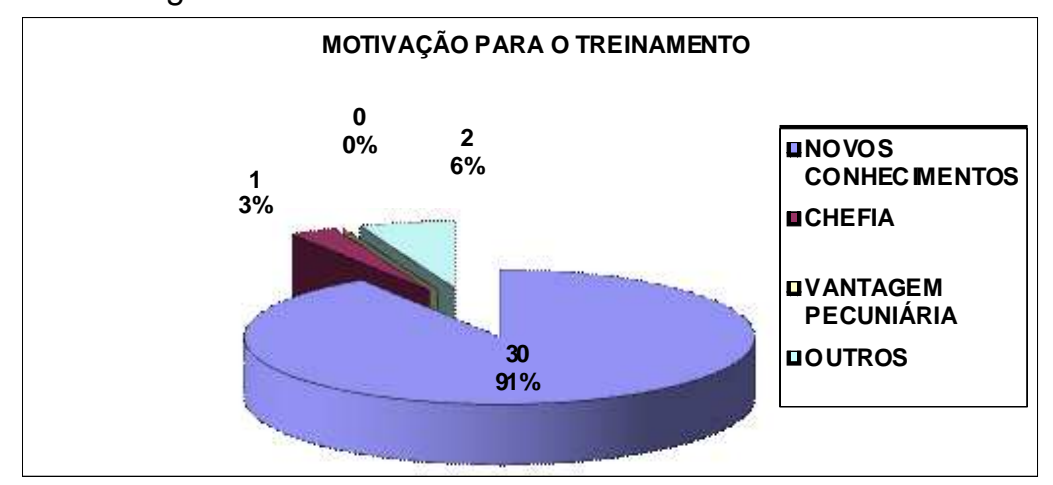

Também foram cogitados possíveis impedimentos para a (maior) participação dos treinandos nos cursos ofertados pela Escola de Governo - EGOV, ou até mesmo em relação ao treinamento amostral (Gestão de Documentos), partindo do pressuposto que tais impeditivos poderiam ter comprometido, mas não impediram o ingresso dos 33 (trinta e três) alunos observados e analisados nesta pesquisa no curso em questão. Dentre as opções sugestionadas - chefia 
interlocutor, horário, desmotivação pessoal, outros - evidenciou-se percentuais consideráveis em todos os itens, inclusive houve a não manifestação por parte de alguns colaboradores da pesquisa em responder a qualquer dos itens, perpetrando a idéia de que nenhum daqueles itens sugeridos poderiam se aplicar à sua realidade. A situação, em termos de impedimento declarado mais presente, dentre as opções ofertadas, foi a de a chefia imediata dos treinamentos não colaborar para a participação dos servidores nestes - resposta dada por $27 \%$ dos entrevistados equivalente a 09 (oito) alunos, assim como o intelocutor foi apontado pelo mesmo percentual de participantes da pesquisa. Seqüencialmente, obteve-se $18 \%$ dos participantes declarando "outros" impeditivos para a não-participação nos cursos, dentre os quais foram especificados o excesso de tarefas na seção de lotação do servidor (grande carga de trabalho, o que colaboraria negativamente para a liberação por parte da chefia destes servidores para participação nos treinamentos), falta de vagas disponíveis, falta de divulgação dos cursos e quantitativo reduzido de servidores nos órgãos de lotação, acarretando em dificuldade para consecução de liberação quando da participação em treinamentos; outros 18\% acreditam que horário (não convidativo ou não equivalente ao seu turno de trabalho) tenha papel fundamental neste problema; outros $10 \%$ alegaram que nenhuma das opções era condizente com sua realidade (ou seja, não marcaram esse item no questionário). Observa-se a equidistribuição de opiniões neste questionamento, diferente de itens como o que abordava o principal "motivador" para a participação do treinando nos cursos ofertados pela Escola de Governo - EGOV. Abaixo, demonstra-se graficamente a divisão de opiniões abordada, ilustrada na Figura 07.

Figura 07: Gráfico dos impedimentos à participação dos treinandos nos cursos.

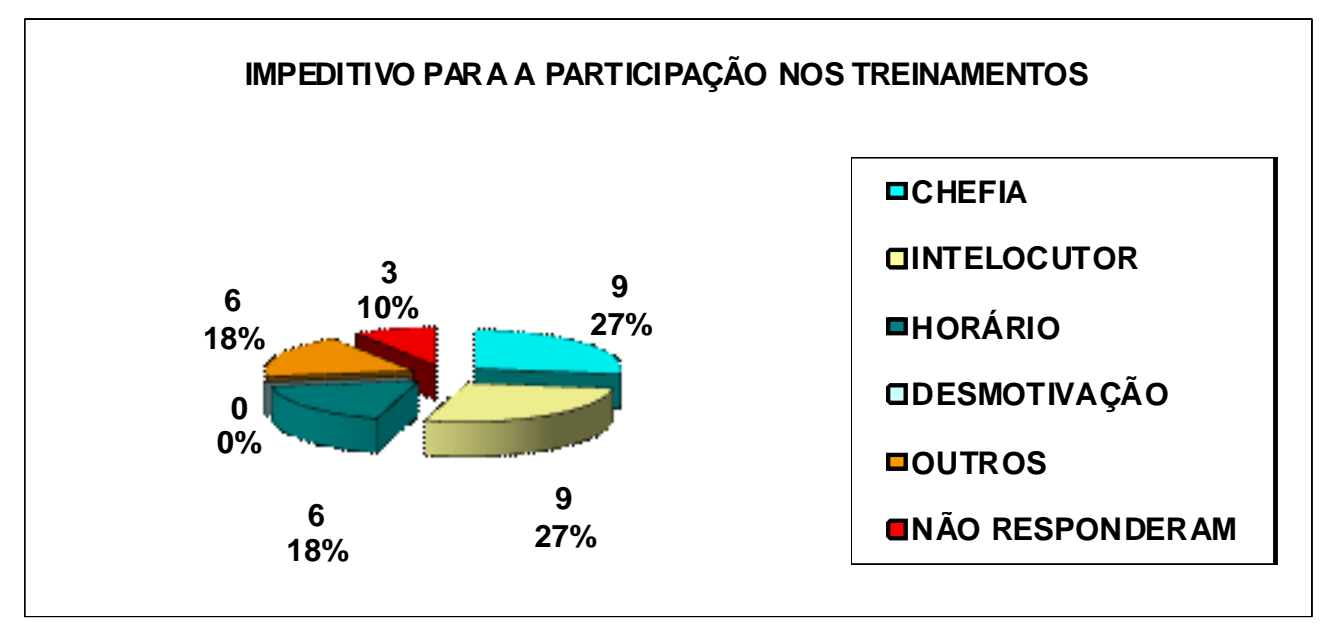


Partindo para a devida avaliação de reação ao Treinamento, verificado por meio do Questionário “Avaliação de Reação ao Treinamento”, reitera-se que o mesmo foi devidamente aplicado junto à população estudada de alunosparticipantes do curso de "Gestão de Documentos" no último dia do curso presencial, conforme anteriormente explicitado neste trabalho.

Considerando as questões aplicadas, a análise estatística feita a respeito de cada questão e a valoração atribuída aos indicadores utilizados para mensurar a efetividade do treinamento junto à população amostral - de 0 a 05 , sendo 0 a resposta quanto à não aplicabilidade do item à realidade do treinando (Não se aplica) e 05 representando que o conceito do servidor quanto à questão proposta é "Ótimo", conforme disposto na Figura 05, verifica-se que os 18 (dezoito) itens tentam transcrever o valor instrumental do treinamento.

Figura 08: Tabela com os indicadores das questões do Questionário de Avaliação de Reação ao Treinamento, proposto por Abbad (1999).

INDICADORES DE MENSURAÇÃO - AVALIAÇÃO DE REAÇÃO

\begin{tabular}{|c|c|}
\hline INDICADORES & VALOR \\
\hline NÃO SE APLICA & 0 \\
\hline RUIM & 1 \\
\hline REGULAR & 2 \\
\hline BOM & 3 \\
\hline MUITO BOM & 4 \\
\hline ÓTIMO & 5 \\
\hline
\end{tabular}

Figura 09: Tabela das Médias, Desvios-Padrão e Moda dos 18 itens do Questionário de Avaliação de Reação ao Treinamento - proposto por Abbad (1999).

\begin{tabular}{|c|c|c|c|c|c|c|}
\hline & Q1 & Q2 & Q3 & Q4 & Q5 & Q6 \\
\hline MÉDIA & 3,88 & 4,03 & 4,09 & 4,34 & 4,30 & 4,25 \\
\hline $\begin{array}{l}\text { DESVIO } \\
\text { PADRÃO }\end{array}$ & 1,01 & 0,97 & 1,00 & 0,81 & 0,85 & 0,92 \\
\hline MODA & 5 & 5 & 5 & 5 & 5 & 5 \\
\hline & Q7 & Q8 & Q9 & Q10 & Q11 & Q12 \\
\hline MÉDIA & 4,28 & 4,21 & 3,91 & 4,03 & 4,19 & 4,30 \\
\hline $\begin{array}{l}\text { DESVIO } \\
\text { PADRÃO }\end{array}$ & 0,58 & 0,74 & 0,84 & 0,75 & 0,82 & 0,88 \\
\hline MODA & 4 & 4 & 4 & 4 & 5 & 5 \\
\hline & Q13 & Q14 & Q15 & Q16 & Q17 & Q18 \\
\hline MÉDIA & 4,45 & 4,25 & 4,21 & 4,13 & 4,48 & 4,36 \\
\hline DESVIO & 067 & 076 & ר 70 & 088 & 57 & 060 \\
\hline $\begin{array}{l}\text { PADRAU } \\
\text { MODA }\end{array}$ & $\begin{array}{r}0,6 / 7 \\
5\end{array}$ & $\begin{array}{r}0,16 \\
4\end{array}$ & $\frac{0,10}{4}$ & $\begin{array}{r}0,00 \\
4\end{array}$ & $\begin{array}{r}5,51 \\
5\end{array}$ & $\frac{0,00}{4}$ \\
\hline
\end{tabular}

Dentro do contexto do indicador "Quanto à Programação", formam propostos quatro itens para sua devida medição. $\mathrm{O}$ item 01 , o qual indaga se a carga horária 
programada para as atividades teóricas do curso foi satisfatória, tem como média de resultados 3,88 , levando em consideração a escala adotada para avaliar a reação dos treinandos ao treinamento e de desvio-padrão, obteve-se o valor 1,01. Observou-se uma variação de respostas de Regular a Ótimo, com predominância da valoração "Ótimo". O item 02 - o qual perguntou aos participantes se a carga horária diária estava adequada, apresentou a média 4,03 e verifica-se uma preponderância nas respostas dos alunos da valoração "Ótimo", segundo a escala definida por Abbad (1999). O desvio-padrão das respostas dos entrevistados foi 0,97. O item 03, em que se abordou a compatibilidade dos objetivos dos cursos com as necessidades de treinamento, obteve-se média 4,09 e desvio padrão 1,00, como predominância da valoração "Ótimo" no quantitativo geral de respostas dos treinandos. O item 04, que aborda a adequação do conteúdo aos objetivos do curso, foi verificado a média 4,34, com desvio padrão 0,81 - o menor desvio dentre os quatro itens que compõem o indicador "Quanto à Programação". Ressalta-se que a moda (predominância de resposta) referente ao item em questão foi a valoração "Ótimo". Verifica-se que o indicador supracitado tem sua cerne na questão planejamento sistemático do ensino, conforme explicitado no Referencial Teórico deste trabalho com o entendimento de Abbad et. al (2006), os quais especificam que o plano instrucional (...) descreve os procedimentos, recursos, meios instrucionais e cargas horárias estimadas de aplicação, para quando da execução do treinamento, tais itens (carga horária, adequação de objetivos) estarem adequados à realidade do curso.

Partindo para o indicador "Aplicabilidade e Utilidade do Treinamento", dois foram os itens sugeridos para mensurá-lo. O item 05 , que faz relação entre a utilidade dos conhecimentos e habilidades enfatizadas no treinamento e a resolução de problemas no trabalho, obteve-se média 4,30 e desvio-padrão 0,85, com preponderância de aparições das respostas "Otimo". Já o item 06, que se refere à possibilidade de aplicação, em curto prazo, dos conhecimentos adquiridos na execução de suas tarefas no trabalho, os respondentes penderam para a valoração "Ótimo" no cômputo geral de respostas, e teve-se média 4,25 e desvio-padrão 0,92.

Quanto ao indicador "Resultados do Treinamento", seis itens mensuram tal situação. O item 07, referente à assimilação do conteúdo transmitido no curso, obteve média 4,28 e o segundo menor desvio padrão de toda a pesquisa - 0,58. 0 item 08, que aborda a probabilidade de melhorar os níveis de desempenho no 
trabalho como resultado do uso das novas habilidades, teve média 4,21 e desvio padrão 0,74. O item 09, que trata da capacidade de transmitir os conhecimentos adquiridos no treinamento a outros servidores (que envolve os quesitos autoconfiança e autocrítica ao nível de aprendizagem), verificou-se a obtenção da média 3,91 e desvio padrão 0,84, demonstrando uma significativa alteração de impressão dos demais itens que abordam aspectos extrínsecos ao individuo, deste questionamento que leva em consideração um aspecto intrínseco (sua percepção personalíssima quanto ao suporte informacional do treinamento na situação de repasse do que foi aprendido para outrem). No item 10, que aborda a probabilidade de promover melhorias nas atividades desenvolvidas pelo seu grupo de trabalho, com base nas habilidades aprendidas no treinamento, verificaram-se média 4,03 e desvio padrão 0,75 . O item 11, quanto ao estímulo decorrente do treinamento para aplicar, no trabalho, os conhecimentos e habilidades aprendidas, teve média 4,19 e desvio padrão 0,82 . Com relação ao item 12, sobre a intenção de aplicar no trabalho os conhecimentos adquiridos no curso, obtiveram-se média 4,30 e desvio padrão 0,88 . Os dois últimos itens do indicador acima explicitado corroboram a idéia da motivação para transferir, explanada por Lacerda e Abbad (2003) outrora neste trabalho como sendo (...) objetivo principal de muitos cursos - aumentar a disposição dos participantes para usar, no trabalho, o material visto no programa.

O indicador "Desempenho Didático", relativo à atuação do instrutor em toda a dinâmica de treinamento constatada por esta pesquisa, sugeriram-se seis outros itens para avaliar a impressão dos participantes sobre o suporte à transferência por parte do mediador do processo informacional - o professor-instrutor. O item 13, que aborda a transmissão dos objetivos do treinamento, teve média 4,45 e desvio padrão 0,67, com predominância de avaliação ótima por parte dos treinandos. No item 14 , quanto ao nível de organização da apresentação da sequência de unidades, obtevese média 4,25 e desvio padrão 0,76. O item 15, quanto ao nível de profundidade de abordagem dos temas, conseguiu média 4,21 e desvio padrão 0,70. O item 16, quanto ao uso de estratégias para motivar os treinandos em relação aos temas abordados, teve média 4,13 e desvio padrão 0,88. Verificou-se que os três últimos itens descritos obtiveram predominância de respostas "Muito Bom" ao invés de "Ótimo" como verificado na maioria dos itens anteriormente descritos. No item 17, referente à qualidade da apresentação dos conteúdos e da exemplificação, foram constatados a maior média e o menor desvio padrão de toda a pesquisa - média 
4,48 e desvio padrão 0,57, valores que se contrapõem aos resultados obtidos nos itens anteriores. E finalizando a análise dos itens, verifica-se que o item 18, o qual aborda o uso de estratégias instrucionais (estudos de caso, exposições orais, discussões em grupo e similares) em relação à apreensão dos conteúdos, obtiveram média 4,36 e desvio padrão 0,60, resultados que se aproximam aos do item 17 . Ressalta-se o fato de os dois últimos itens deste indicador terem a predominância da valoração "Ótimo".

No campo de "Observações", deu-se a oportunidade para os treinandos de expressar opiniões, concordância, discordância e sugestões sobre aquela avaliação e sua impressão sobre o curso. Observou-se que poucas foram as manifestações neste campo específico, mas todas foram de elogios ao curso, à iniciativa de promover a avaliação do mesmo para posteriores contribuições e sugestões do presente trabalho e a explicitação da necessidade da realização de mais cursos como o amostral (Gestão de Documentos) para o melhoramento do desempenho dos treinandos na execução de suas atividades.

Após a explicitação de todos os resultados obtidos através dos 02 (dois) questionários aplicados, é possível inferir que a reação ao treinamento junto à população analisada foi perceptível e ocorreu de uma forma positiva, haja vista os altos valores (médias) obtidos no segundo questionário, desenvolvido para avaliar esta variável. Fatores como satisfação, motivação, efetividade, aquisição de conhecimento, entre outros, foram analisados e mensurados nos mencionados instrumentos de pesquisa, e com os valores atribuídos a tais fatores e, por conseguinte, considera-se que houve boa resposta em relação à amostra analisada.

Cabe mencionar com relação à maior congruência nos resultados do referido Questionário "Avaliação de Reação ao Treinamento", no qual foram abordados questionamentos que tentavam mensurar aprendizagem, estímulo a aplicação dos conhecimentos, programação do treinamento, assimilação, atuação do instrução, entre outras, observa-se que a obtenção de dados finais mais fidedignos à realidade geral dos treinandos (servidores público do DF) ocorreria caso houvesse a possibilidade de aplicar os mesmos instrumentos de coleta de dados em outras amostras, em diferentes contextos educacionais e períodos, o que permitiria resultados mais aprofundados sobre o assunto, porém seria inviável para a pesquisadora e para a presente pesquisa, devido à falta de tempo hábil para tal. 


\section{CONCLUSÕES E RECOMENDAÇÕES}

Embora a presente pesquisa não possa chegar a conclusões mais exata dos efeitos da reação ao treinamento, levando em consideração o tamanho da amostra ser pequeno diante do quantitativo geral de servidores públicos da Administração Pública do Distrito Federal, percebe-se que houve a aprovação da população treinanda amostral quanto ao treinamento promovido e evidencia-se que as ações de TD\&E promovidas pela EGOV precisam melhorar seu alcance e abrangência.

Para alcançar a eficiência e a excelência na promoção da capacitação para os servidores, as organizações públicas precisam ser capazes de otimizar seus recursos, sejam eles físicos, financeiros, patrimoniais, bem como criar e estruturar modelos de gestão do capital humano e dos talentos. Foi possível observar que a EGOV, com todas as suas ações e planos para implementar a promoção da capacitação e do treinamento para os servidores do GDF, ainda incorre no erro de não trabalhar a divulgação de seus trabalhos, de suas intenções e planos junto aos maiores beneficiários de todo esse processo - os servidores -, como pôde ser constatado por meio da pesquisa de opinião e explicitado na parte de "Resultados".

Por ser uma atividade estratégica da gestão pública moderna, a "Gestão de Pessoas" precisa estar sempre presente nas ações e compromissos do Ente Público com seu corpo funcional, haja vista a importância de promover os preceitos e entendimentos de tal forma de Gestão aplicada aos colaboradores em geral, para uma melhor condução de toda a sistemática que vem a ser o "trabalho". O Governo do Distrito Federal tem se mostrado interessado em ver esse lado, que garante melhorias para os servidores como um todo, como pôde ser vislumbrado através da publicação dos Decretos que instituíram a Política de Gestão de Pessoas, a Política de Capacitação para os Servidores, sendo essas legislações mecanismos de promoção e incentivo para o TD\&E junto aos agentes públicos desta esfera.

Em vista do que foi constatado na presente pesquisa, fica a sugestão à EGOV de dar continuidade aos trabalhos de promoção à capacitação, mesmo diante de uma celeuma de novidades em termos de legislação que não permitiram que a mencionada Instituição pudesse ainda mensurar o impacto e a receptividade em favor dos servidores do GDF, porém com a ressalva de que precisa haver melhor disseminação de todos os planos de capacitação, mudando a impressão de que os 
servidores só precisam "ser capacitados", e sim tem a obrigação e o dever de fazerem parte desse processo de construção de alicerces e mecanismos de melhoramento para suas carreiras.

Ressalta-se que, segundo dados da Escola de Governo do Distrito Federal, além do treinamento objeto de análise deste trabalho, foram promovidos até o final do mês de Dezembro de 2010 cerca de 150 outros cursos de capacitação para servidores do GDF, o que caracteriza a intenção do governo em capacitar seus colaboradores.

Diante das conclusões obtidas através da pesquisa realizada, que foram animadoras por comprovarem os efeitos positivos e nada foi evidenciado em termos de negatividades quanto aos itens propostos para Avaliação da Reação ao Treinamento junto aos servidores analisados, o que permite inferir que tais resultados são um reflexo dos cursos ofertados com a finalidade de propiciar novos conhecimentos e aperfeiçoamento aos agentes públicos, sugere-se a continuidade deste tipo de pesquisa, abrangendo outros grupos de servidores, com características destoantes das apresentadas por estes (participantes analisados), para corroborar ou confrontar os dados obtidos e os resultados aferidos. 


\section{CRONOGRAMA DE EXECUÇÃO DAS ETAPAS}

O cronograma, representação gráfica de previsão da execução da presente pesquisa, pode ser verificado na tabela abaixo. Ressalta-se que não se estabeleceu prazo exato (dia) para o cumprimento das etapas subseqüentes à Entrega do Projeto, apenas a previsão do mês no qual cada uma destas etapas ulteriores foi programada para ser realizada.

\begin{tabular}{|c|c|c|c|c|c|}
\hline \multirow[b]{2}{*}{ ETAPAS } & \multicolumn{5}{|c|}{ DATAS } \\
\hline & Junho & Setembro & Outubro & Novembro & Dezembro \\
\hline Entrega do projeto & $28 / 06$ & & & & \\
\hline Coleta de dados & & & OK & & \\
\hline Tabulação dos dados & & & OK & & \\
\hline Análise e discussão dos resultados & & & OK & & \\
\hline Redação final da monografia & & & & OK & \\
\hline Defesa oral & & & & & $04 / 12$ \\
\hline Entrega do relatório final & & & & & $15 / 12$ \\
\hline
\end{tabular}




\section{REFERÊNCIAS}

ABBAD, G. Um modelo integrado de avaliação de impacto de treinamento no trabalho. Tese de Doutorado, Universidade de Brasília, Brasília, 1999.

ABBAD, G. Medidas de avaliação de procedimentos, processos e apoio instrucionais em de TD\&E. In J. E. Borges-Andrade, G. Abbad, \& L. Mourão (orgs.). Treinamento, desenvolvimento e educação em organizações e trabalho: fundamentos para a gestão de pessoas. Porto Alegre, Artmed, 2006.

ABBAD, G. S.; BORGES-ANDRADE, J. E. Aprendizagem humana em organizações de trabalho. In: Zanelli, J. C; Borges-Andrade, J, E; Bastos, A. V. B (Org.). Psicologia, organizações e trabalho no Brasil. Porto Alegre: Artmed, 2004.

ABBAD, G. S; FREITAS, I. A; PILATI, R. Contexto de Trabalho, desempenho competente e necessidades. (In) J. E. Borges-Andrade, G. S. Abbad, \& L. Mourão (Orgs.), (2006). Treinamento, desenvolvimento e educação em organizações e trabalho: Fundamentos para gestão de pessoas. Porto Alegre: Artmed.

ABBAD, G. E; LACERDA, E. R. M. Impacto do Treinamento no Trabalho: investigando variáveis motivacionais e Organização como suas preditoras. Revista de Administração Contemporânea, v.7, n.4, pág. 77-96, Out./Dez. 2003.

ABBAD, G. S; ZERBINI, T; CARVALHO, R. S; E, MENESES, P. P. M. Planejamento Instrucional em TD\&E. . (In) J. E. Borges-Andrade, G. S. Abbad, \& L. Mourão (Orgs.), (2006). Treinamento, desenvolvimento e educação em organizações e trabalho: Fundamentos para gestão de pessoas. Porto Alegre: Artmed

BASTOS, A. V. B.; CORREA, N. C. N.; LIRA, S. B. Padrões de comprometimento com a profissão e a organização: o impacto de fatores pessoais e da natureza do trabalho. In: ENCONTRO ANPAD, 22, 1998, Foz do Iguaçu, 1998. 
BORGES-ANDRADE, J. E; PEREIRA, M. H. G., PUENTE-PALÁCIOS, K. E. \& Morandini D. C. Impacto individual e organizacional de treinamento: Uma análise com base num modelo de avaliação institucional e na teoria multinível. Psicologia: Organizações e Trabalho, 2, 117-146. 2002.

BRASIL. Constituição (1988). Constituição da Republica Federativa do Brasil. Brasília, DF: Senado Federal.

BOOG, G.G. Manual de Treinamento e Desenvolvimento. 2ª Ed. São Paulo, Ed. Makron Books, 1994.

CAMPOS, K.C, E; BARDUCK, A. L. J, E; MARQUES, D.G, E; RAMOS, K.P, E; SANTOS, L, A, D, E; BECKER, T, J. Avaliação de Sistema de Treinamento e Desenvolvimento em Empresas Paulistas de Médio e Grande Porte. Psicologia: Reflexão e Crítica, 2004, 17(3), pp. 435-446.

CANABRAVA, T., E; VIEIRA, O.F.A. Treinamento e Desenvolvimento para empresas que aprendem. Brasília, Editora Sesc - DF, 2006.

DISTRITO FEDERAL (Estado). DECRETO №. 29.814/2008 - Política de Gestão de Pessoas do Governo do Distrito Federal.

DISTRITO FEDERAL (Estado). DECRETO №. 31.453, de 22 de Março de 2010 - a Política de Capacitação e Desenvolvimento para os servidores da Administração Direta, Autárquica e Fundacional do Distrito Federal.

DISTRITO FEDERAL (Estado). Portaria SEPLAG №. 337, de 15 de Dezembro de 2009 - institui o Plano de Capacitação 2010.

ESCOLA DE GOVERNO DO DISTRITO FEDERAL. Apresentação e Estrutura física. Disponível em: www.escoladegoverno.seplag.df.gov.br. Acessado em 06 de Dezembro de 2010. 
FREITAS, I. A; BORGES-ANDRADE, J. E. Efeitos de Treinamento nos desempenhos individual e organizacional. RAE (FGV), v. 44, n. 3, p. 44-56, 2004.

MOURÃO, L. Oportunidades de qualificação profissional no Brasil: reflexões a partir de um panorama quantitativo. RAC, vol.13, o․ 01, Curitiba Jan./Mar. 2009.

OLIVEIRA, M.C.A, E; LIMA, L.E.L. Síntese da evolução histórica do IDR. 2ª Ed, Brasília: Instituto de Desenvolvimento de Recursos Humanos, 1999.

OLIVEIRA, N.M, E; VANALLE, R.M. Treinamento como dimensão competitiva nas organizações. Revista de Ciência \& Tecnologia • 14 - pp. 85-92, 1999.

PACHECO, L. E; SCOFANO, A, C. E; BECKERT, M. E; SOUZA, V. Capacitação e Desenvolvimento de Pessoas. Editora FGV, 2008.

PILATI, R. História e importância de TD\&E. In J. E. Borges-Andrade, G. Abbad, \& L. Mourão (orgs.). Treinamento, desenvolvimento e educação em organizações e trabalho: fundamentos para a gestão de pessoas. Porto Alegre, RS: Artmed.

SUGEP-SEPLAG. Consultoria Interna - Sistema de Gestão de Pessoas (SIGEP) - a Gestão de Pessoal em números. Sistema SIGRH - GDF. Maio, 2009.

VARGAS, M. R. M. Treinamento e desenvolvimento: reflexões sobre seus métodos. Revista de Administração, 31(2), 126-136, 1996.

VARGAS, M.R.V. \& ABBAD, G. S. Em J. E. Borges-Andrade, G. S. Abbad, \& L. Mourão (Orgs.),(2006). (in) Treinamento, desenvolvimento e educação em organizações e trabalho: Fundamentos para gestão de pessoas. Porto Alegre: Artmed.

VERGARA, S.C. Projetos e Relatórios de Pesquisa em Administração. 10ª ed. São Paulo: Atlas, 2009 


\section{APÊNDICES}

\section{Apêndice A - Cartas de Apresentação}

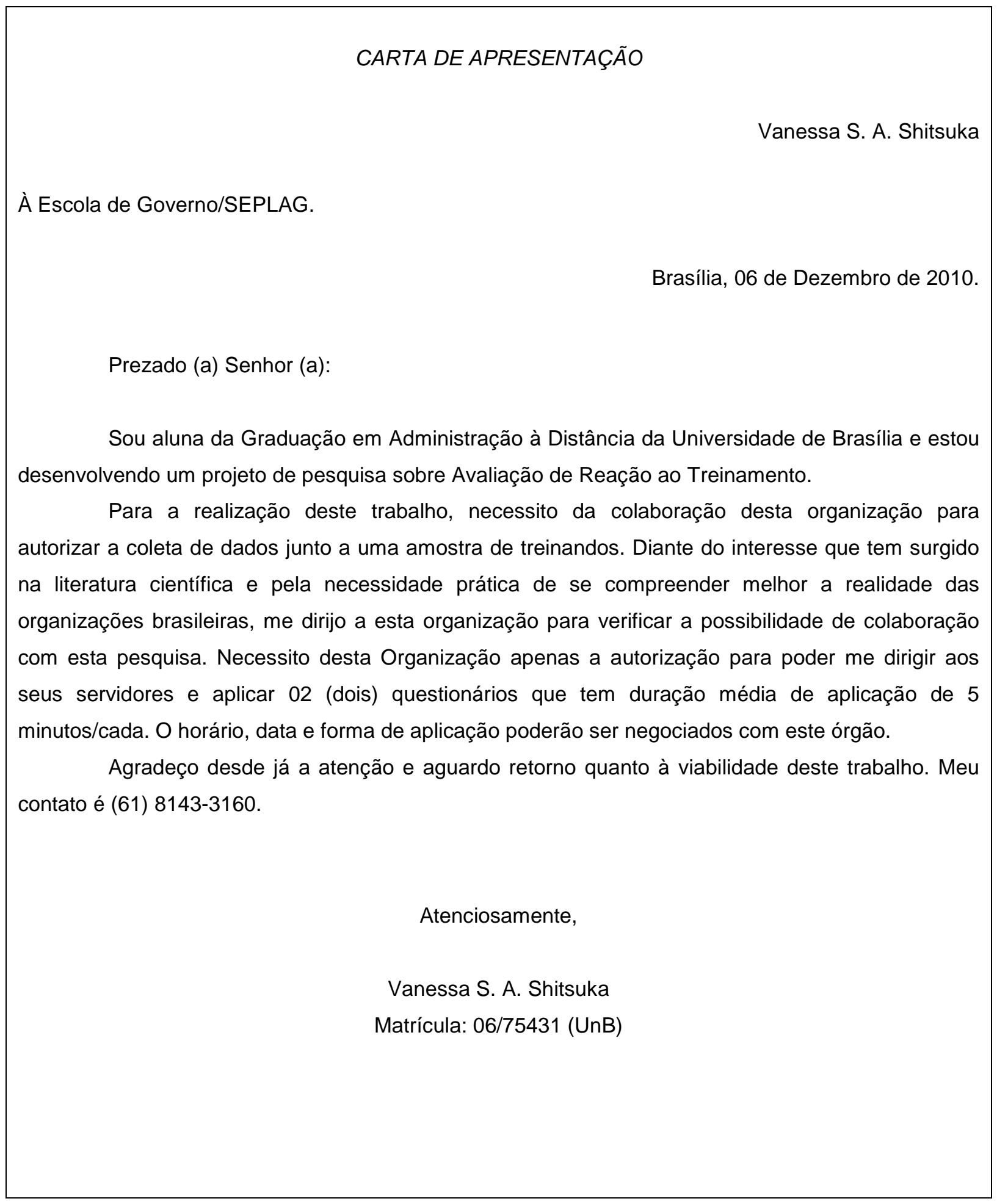


CARTA DE APRESENTAÇÃO

Vanessa S. A. Shitsuka

Aos participantes do Curso "Gestão de Documentos".

Brasília, 08 de Dezembro de 2010.

Prezado (a) Senhor (a):

Sou aluna da Graduação em Administração à Distância da Universidade de Brasília e estou desenvolvendo um projeto de pesquisa sobre Avaliação de Reação ao Treinamento.

Para a realização deste trabalho, necessito da anuência dos senhores para a aplicação individual (por treinando) de 02 (dois) questionários, sendo um (Questionário "SÓcIODEMOGRÁFICO E PROFISSIONAL".) a ser realizado no terceiro dia de treinamento (hoje), e o outro (Questionário "AVALIAÇÃO DE REAÇÃO AO TREINAMENTO") no último dia do Curso de Capacitação a ser objeto da pesquisa, com a finalidade de mensurar o quanto o presente curso beneficiará provocará mudança de comportamento nos treinandos. O tempo médio de duração para responder as questões é de 5 minutos,

Cabe ressaltar que tal ferramenta de pesquisa não pretende identificar quaisquer participantes, sendo mantido o sigilo do servidor pesquisado.

Agradeço desde já a atenção e conto com a colaboração de todos!

Atenciosamente,

Vanessa S. A. Shitsuka

Matrícula: 06/75431 (UnB) 


\section{Apêndice B - Questionários}

\section{Questionário "Sócio Demográfico e Profissional"}

Caro Treinando,

Este questionário tem o objetivo de colher informações sócio-demográficas e profissionais dos participantes deste Treinamento. Desde já agradecemos sua colaboração.

Ao lado de cada item, há duas ou mais alternativas. Marque apenas uma resposta para cada item.

1) Qual é o seu sexo? Feminino ( ) Masculino ( )

2) Sua faixa etária: 21-30（） 31-40（） 41-50（） 51 em diante ( )

3) A qual cargo pertence? Auxiliar ( ) Técnico ( ) Analista ( ) Outro ( )

4) Qual é seu nível de escolaridade? Fundamental ( ) Médio ( ) Superior ( )

5) Qual é seu tempo de serviço no cargo o qual ocupa? anos

6) Qual é seu principal motivo para participar deste Treinamento? Novos Conhecimentos/Experiência

( ) Pedido da Chefia ( ) Vantagem Pecuniária ( ) Outro ( ) Especifique:

7) Qual é a principal fator que normalmente dificulta sua participação em Treinamentos? Chefia ( ) Interlocutor ( ) Horário ( ) Desmotivação ( ) Outro ( ) Especifique: 


\section{Questionário "Avaliação de Reação ao Treinamento"}

Caro Treinando,

Este questionário tem o objetivo de colher informações acerca de diferentes aspectos do treinamento de acaba de ser ministrado. Procure responder da forma mais precisa possível às questões que se seguem. Desde já agradecemos sua colaboração.

Ao lado de cada indicador há uma escala com seis conceitos de julgamento (ÓTIMO, MUITO BOM, BOM, REGULAR, RUIM E NÃO SE APLICA - N/A). Leia cada indicador cuidadosamente, escolha o ponto da escala que melhor descreve a sua opinião acerca do módulo e assinale com um " $X$ " dentro do espaço correspondente ao seu julgamento.

\begin{tabular}{|c|c|c|c|c|c|c|}
\hline \multicolumn{7}{|l|}{ INDICADORES } \\
\hline QUANTO Á PROGRAMAÇÃO & Ótimo & $\begin{array}{l}\text { Muito } \\
\text { Bom }\end{array}$ & Bom & Regular & Ruim & $\mathrm{N} / \mathrm{A}$ \\
\hline \multicolumn{7}{|l|}{$\begin{array}{l}\text { 1) Carga horária programada para as } \\
\text { atividades teóricas. }\end{array}$} \\
\hline \multicolumn{7}{|l|}{ 2) Carga horária diária. } \\
\hline \multicolumn{7}{|l|}{$\begin{array}{l}\text { 3) Compatibilidade dos objetivos do curso com } \\
\text { as necessidades de treinamento. }\end{array}$} \\
\hline \multicolumn{7}{|l|}{$\begin{array}{l}\text { 4) Adequação do conteúdo aos objetivos do } \\
\text { curso. }\end{array}$} \\
\hline $\begin{array}{l}\text { APLICABILIDADE E UTILIDADE DO } \\
\text { TREINAMENTO }\end{array}$ & Ótimo & $\begin{array}{l}\text { Muito } \\
\text { Bom }\end{array}$ & Bom & Regular & Ruim & $\mathrm{N} / \mathrm{A}$ \\
\hline \multicolumn{7}{|l|}{$\begin{array}{l}\text { 5) Utilidade dos conhecimentos e habilidades } \\
\text { enfatizadas no treinamento para a resolução } \\
\text { de problemas de trabalho. }\end{array}$} \\
\hline \multicolumn{7}{|l|}{$\begin{array}{l}\text { 6) Possibilidade de aplicação, a curto prazo, } \\
\text { dos conhecimentos adquiridos na execução de } \\
\text { suas tarefas no trabalho. }\end{array}$} \\
\hline RESULTADOS DO TREINAMENTO & Ótimo & $\begin{array}{l}\text { Muito } \\
\text { Bom }\end{array}$ & Bom & Regular & Ruim & $\mathrm{N} / \mathrm{A}$ \\
\hline \multicolumn{7}{|l|}{$\begin{array}{l}\text { 7) Assimilação do conhecimento transmitido no } \\
\text { curso. }\end{array}$} \\
\hline \multicolumn{7}{|l|}{$\begin{array}{l}\text { 8) Probabilidade de melhorar os níveis de } \\
\text { desempenho no trabalho como resultado do } \\
\text { uso das novas habilidades. }\end{array}$} \\
\hline $\begin{array}{l}\text { 9) Capacidade de transmitir os conhecimentos } \\
\text { adquiridos no treinamento a outros servidores. }\end{array}$ & & & & & & \\
\hline
\end{tabular}




\begin{tabular}{|c|c|c|c|c|c|c|}
\hline $\begin{array}{l}\text { 10) Probabilidade de promover melhorias nas } \\
\text { atividades desenvolvidas pelo seu grupo de } \\
\text { trabalho, com base nas habilidades aprendidas } \\
\text { no treinamento. }\end{array}$ & & & & & & \\
\hline $\begin{array}{l}\text { 11) Estímulo decorrente do treinamento para } \\
\text { aplicar, no trabalho, os conhecimentos e } \\
\text { habilidades aprendidas. }\end{array}$ & & & & & & \\
\hline $\begin{array}{l}\text { 12) Intenção de aplicar no trabalho os } \\
\text { conhecimentos adquiridos no curso. }\end{array}$ & & & & & & \\
\hline DESEMPENHO DIDÁTICO (INSTRUTOR) & Ótimo & $\begin{array}{l}\text { Muito } \\
\text { Bom }\end{array}$ & Bom & Regular & Ruim & $\mathrm{N} / \mathrm{A}$ \\
\hline 13) Transmissão dos objetivos do treinamento. & & & & & & \\
\hline $\begin{array}{l}\text { 14) Nível de organização da apresentação da } \\
\text { seqüência de unidades. }\end{array}$ & & & & & & \\
\hline $\begin{array}{l}\text { 15) Nível de profundidade com que os temas e } \\
\text { assuntos foram abordados. }\end{array}$ & & & & & & \\
\hline $\begin{array}{l}\text { 16) Uso de estratégias para motivar os } \\
\text { treinandos em relação aos temas. abordados }\end{array}$ & & & & & & \\
\hline $\begin{array}{l}\text { 17) Qualidade da apresentação dos conteúdos } \\
\text { e da exemplificação. }\end{array}$ & & & & & & \\
\hline $\begin{array}{l}\text { 18) Uso de estratégias instrucionais (estudos } \\
\text { de caso, exposições orais, discussões em } \\
\text { grupo e similares) em relação à apreensão dos } \\
\text { conteúdos. }\end{array}$ & & & & & & \\
\hline
\end{tabular}

OBSERVAÇÕES: Caso considere necessário tecer algum comentário sobre os itens acima, utilize o espaço abaixo: 